\title{
$N-m y c$ Controls Proliferation, Morphogenesis, and Patterning of the Inner Ear
}

\author{
Elena Domínguez-Frutos, ${ }^{1 \star}$ Iris López-Hernández, ${ }^{1 \star}$ Victor Vendrell, ${ }^{1}$ Joana Neves, ${ }^{2}$ Micaela Gallozzi, ${ }^{1}$ Katja Gutsche, ${ }^{1}$ \\ Laura Quintana, ${ }^{3}$ James Sharpe, ${ }^{3}$ Paul S. Knoepfler, ${ }^{4}$ Robert N. Eisenman, ${ }^{5}$ Andreas Trumpp ${ }^{6}$ Fernando Giráldez, ${ }^{2}$ \\ and Thomas Schimmang ${ }^{1}$ \\ ${ }^{1}$ Institute of Biology and Molecular Genetics, University of Valladolid and Spanish National Research Council, E-47003 Valladolid, Spain, ${ }^{2}$ Experimental \\ and Health Sciences, Barcelona Biomedical Research Park and ${ }^{3}$ Catalan Institution for Research and Advanced Studies, European Molecular Biology \\ Laboratory-Centre for Genomic Regulation (CRG) Systems Biology Research Unit, CRG, University of Pompeu Fabra, 08003 Barcelona, Spain, ${ }^{4}$ Department \\ of Cell Biology and Human Anatomy, University of California Davis School of Medicine, Sacramento, California 95817, ${ }^{5}$ Fred Hutchinson Cancer Research \\ Center, Seattle, Washington 98109, and ${ }^{6}$ Deutsches Krebsforschungszentrum, D-69120 Heidelberg, Germany
}

Myc family members play crucial roles in regulating cell proliferation, size, and differentiation during organogenesis. Both $N-m y c$ and $c-m y c$ are expressed throughout inner ear development. To address their function in the mouse inner ear, we generated mice with conditional deletions in either $N$ - $m y c$ or $c$-myc. Loss of $c$-myc in the inner ear causes no apparent defects, whereas inactivation of $N$ - $m y c$ results in reduced growth caused by a lack of proliferation. Reciprocally, the misexpression of $N-m y c$ in the inner ear increases proliferation. Morphogenesis of the inner ear in $\mathrm{N}-\mathrm{m} y \mathrm{c}$ mouse mutants is severely disturbed, including loss of the lateral canal, fusion of the cochlea with the sacculus and utriculus, and stunted outgrowth of the cochlea. Mutant cochleas are characterized by an increased number of cells exiting the cell cycle that express the cyclin-dependent kinase inhibitor p2 $7^{\text {Kip1 }}$ and lack cyclin D1, both of which control the postmitotic state of hair cells. Analysis of different molecular markers in $\mathrm{N}-\mathrm{myc}$ mutant ears reveals the development of a rudimentary organ of Corti containing hair cells and the underlying supporting cells. Differentiated cells, however, fail to form the highly ordered structure characteristic for the organ of Corti but appear as rows or clusters with an excess number of hair cells. The Kölliker's organ, a transient structure neighboring the organ of Corti and a potential source of ectopic hair cells, is absent in the mutant ears. Collectively, our data suggest that $N-m y c$ regulates growth, morphogenesis, and pattern formation during the development of the inner ear.

\section{Introduction}

The inner ear is derived from the otic placode that, during invagination, forms the otic vesicle. Growth and mophogenesis of the otic vesicle is coordinated by proliferation and apoptosis of cells that lead to a complex series of morphogenetic changes, resulting in the creation of distinct vestibular and cochlear regions. In the vestibular region, sensory epithelia corresponding to the utricular and saccular maculae and the ampullary cristae of the semicircular canals are found. As the cochlear duct elongates, a subset of cells in its ventral part develop as the sensory epithelium or organ of Corti. The structure of the organ of Corti is character-

Received Feb. 14, 2011; accepted March 23, 2011.

Author contributions: T.S. designed research; E.D.-F., I.L.-H., V.V., J.N., M.G., K.G., L.Q., and T.S. performed research; J.S., P.S.K., R.N.E., and A.T. contributed unpublished reagents/analytic tools; J.N., F.G., and T.S. analyzed data; T.S. wrote the paper.

${ }^{*}$ E.D.-F. and I.L.-H. contributed equally to this work.

This work was supported by Ministerio de Ciencia e Innovación Grants BFU2010-15477 and PLE 2009-0098, Ciberned, TerCel, and Red de Terapia Célular de Castilla y León to T.S., and Grant R37CA57138 to R.N.E. We thank H. Winter for establishing techniques in our laboratory, J. Johnson for Atoh1 antibodies, U. Pirvola and E. Rubel for technical advice, the confocal microscope service of the Institute of Biology and Molecular Genetics and Faculty of Medicine of University of Valladolid, Cristina Pujades, and Mark Maconochie for comments on this manuscript.

Correspondence should be addressed to Thomas Schimmang, Institute of Biology and Molecular Genetics, University of Valladolid and Spanish National Research Council, C/Sanz y Forés 3, E-47003 Valladolid, Spain. E-mail: schimman@ibgm.uva.es.

DOI:10.1523/JNEUROSCI.0785-11.2011

Copyright $\odot 2011$ the authors $\quad 0270-6474 / 11 / 317178-12 \$ 15.00 / 0$ ized by inner hair cells (IHCs) and outer hair cells (OHCs), which are arranged in ordered rows along the length of the cochlea. Hair cells are accompanied by several types of supporting cells (Kelley, 2006; Bok et al., 2007a; Kelly and Chen, 2009).

Three main cell types are derived from the otic vesicle, including the nonsensory, sensory (future hair cells and the associated supporting cells), and neuronal lineages. Several studies demonstrate that sensory development requires Notch signaling (Daudet and Lewis, 2005; Kiernan et al., 2006; Hartman et al., 2010; Pan et al., 2010) and the transcription factor Sox2 (Kiernan et al., 2005; Dabdoub et al., 2008; Neves et al., 2011). As development continues, prosensory cells within the cochlea upregulate the cyclin dependent kinase inhibitor (cdki) p27 $7^{\text {kip } 1}$ (Chen and Segil, 1999). The timing of $\mathrm{p} 27^{\mathrm{kip} 1}$ expression correlates with terminal mitosis within the prosensory domain and closely precedes the first signs of hair cell differentiation (Lee et al., 2006). During hair cell differentiation, downregulation of cyclin D1 is observed, which has been postulated as a prerequisite for the maintenance of their postmitotic state (Laine et al., 2010).

The $m y c$ proto-oncogene family (comprising $c-m y c, N-m y c$, and $L-m y c$ ) is one of the most studied groups of genes in biology. Myc proteins integrate signals to modulate diverse processes, such as proliferation, growth, apoptosis, and differentiation (Hurlin, 2005; Eilers and Eisenman, 2008). Mice lacking N-myc or $c-m y c$ die at embryonic day 11.5 (E11.5) or E10.5, respectively 
(Sawai et al., 1993; Trumpp et al., 2001), thereby limiting the analysis of inner ear development to early stages. Mice lacking $L-m y c$ are viable and have no discernible defects (Hatton et al., 1996).

The development of mice containing conditional alleles of the $c-m y c$ and $N-m y c$ genes provide the opportunity to perform more detailed studies of defects caused by their deficiency in specific tissues and organ systems (Knoepfler et al., 2002). Here we have analyzed the consequences of loss of $c-m y c$ and $N-m y c$ in the inner ear. Whereas $c-m y c$ mutants show no inner ear defects, $\mathrm{N}-m y c$ deletion severely perturbs inner ear development. The resulting phenotypes suggest that N-Myc regulates critical developmental steps, such as growth of the otic vesicle, formation of the lateral semicircular canal, separation of sensory epithelia, and patterning of the organ of Corti.

\section{Materials and Methods}

Transgenic mice. The following mouse lines and their genotyping have been described previously: $N-m y c^{\text {flox/flox }}$ (Knoepfler et al., 2002), c-my$c^{\text {flox/flox }}$ (Trumpp et al., 2001), the ROSA26 Cre reporter strain (Soriano, 1999), transgenic mice carrying a Cre gene under the control of Pax2 regulatory regions (Ohyama and Groves, 2004) (obtained by the Mutant Mouse Regional Resource Centers), and a mouse line in which Cre has been targeted to the Foxg1 locus (Hébert and McConnell, 2000). The expected mendelian inheritance pattern is seen in $\mathrm{N}$-myc mutants created by Pax2Cre: 58 mutants of 237 animals (24.5\%). This is not the case for $N$-myc mutants created by Foxg1Cre ( 35 mutants of 365 animals, corresponding to $9.6 \%$ ) because $N-m y c$ and Foxg1 localize to the same chromosome. The lethality of Foxg1Cre-N-Myc mutants may be influenced by heterozygous loss of the Foxg1 coding region attributable to its replacement by the Cre gene (Hébert and McConnell, 2000).

$R T-P C R$. RNA was isolated from otic vesicles, whole inner ears including the otic capsule, or the dissected cochlear sensory epithelia using the RNA NOW kit (Biogentex). Two micrograms of RNA was reverse transcribed with the Transcriptor First Strand cDNA Synthesis kit (Roche). The following primers were used: $c-m y c, 300 \mathrm{bp}$, sense TCACCAGCACAACTACGCCG and antisense CAGGATGTAGGCGGTGGCTT; $N-m y c, 345$ bp, sense CAGCTGCACCGCGTCCACCATGCCGGGGAT GATCTGC and antisense CATGCAGTCCTGAAGGATGACCGGATTAGGAGTGAG; gapdh, 441 bp, sense AACGGGAAGCCCATCACC and antisense CAGCCTTGGCAGCACCAG. Cycling was conducted at $95^{\circ} \mathrm{C}$ for $5 \mathrm{~min}$ initially followed by 35 cycles of the following: $95^{\circ} \mathrm{C}$ for $30 \mathrm{~s}$ $(c-m y c, N-m y c, g a p d h), 55^{\circ} \mathrm{C}(c-m y c, g a p d h)$ or $65^{\circ} \mathrm{C}(N-m y c)$ for $30 \mathrm{~s}$, and $72^{\circ} \mathrm{C}$ for $30 \mathrm{~s}$.

Histology and RNA in situ hybridization. Preparation of histological sections stained with hematoxylin and eosin, RNA whole-mount in situ hybridization using riboprobes for Lunatic fringe (LFng) and NeuroD (Morsli et al., 1998; Vázquez-Echeverría et al., 2008), $\beta$-galactosidase staining, and the sectioning of stained embryos (Alvarez et al., 2003) has been described previously. For detection of $N-m y c$ mRNA, a probe encoding the complete cDNA was used (MG207382; Origene).

$N$-myc gain of function. For in ovo electroporation, fertilized hen's eggs were incubated until embryos reached Hamburger-Hamilton stage HH12-HH14 (Hamburger and Hamilton, 1992). An expression vector carrying $N$-myc under the control of the CMV promoter $(1.7 \mu \mathrm{g} / \mu \mathrm{l})$ and a GFP reporter plasmid pCIG $(0.75 \mu \mathrm{g} / \mu \mathrm{l})$ and fast green $(0.4 \mu \mathrm{g} / \mu \mathrm{l})$ were injected into the right otic cup by gentle air pressure through a micropipette. The platinum electrode was placed next to the otic cup and the anode electrode parallel to it on the other side of the embryo. Square pulses (eight pulses of $10 \mathrm{~V}, 50 \mathrm{~Hz}, 250 \mathrm{~ms}$ ) were generated by a CUY-21 square-wave electroporator (BEX). The left otic vesicle was not injected and was always used as control. Ectopic expression of N-myc was detected using an antibody against N-myc purchased from Santa Cruz Biotechnology (C19, sc7091). This antibody does not detect endogenous $\mathrm{N}$-myc in chicken embryos. Ectopic $\mathrm{N}$-myc expression was reliably detected after $6 \mathrm{~h}$ but not at $24 \mathrm{~h}$, most likely because of the high turnover rate of $\mathrm{N}$-myc. Otic vesicle size and proliferation rate were assessed by $3 \mathrm{D}$ reconstructions and $\mathrm{pH} 3$ labeling, respectively. Electroporated embryos were collected $24 \mathrm{~h}$ after electroporation and selected for high GFP expression in the otic vesicle. Embryos were fixed overnight in $4 \%$ PFA/PBS, imbedded in $7.5 \%$ gelatin/15\% sucrose, cryosectioned, and processed for immunohistochemistry against $\mathrm{pH} 3$ (rabbit, 1:400; Millipore) on serial sections encompassing the whole otic vesicle. Immunolabeling was detected with secondary antibody anti-rabbit IgG Alexa Fluor-594, and sections were counterstained with 4',6-diamidino-2phenylindole (DAPI) (100 ng/ml; Invitrogen) and mounted in Mowiol (Calbiochem). Images were obtained by conventional fluorescence microscopy (Leica DMRB fluorescence microscope fitted with a Leica DC300F CCD camera). The calculation of volume and surface area of the otic vesicle was done by three-dimensional reconstructions from serial 20 $\mu \mathrm{m}$ sections using BioVis3D software. They were calculated for four independent electroporated otic vesicles and for the corresponding controls. Values in electroporated otic vesicles were referred to controls that were arbitrarily set to one. To assess cell proliferation rate, the number of phosphorylated histone $\mathrm{H} 3$ ( $\mathrm{pH} 3$ )-positive cells was counted in all serial sections of each otic vesicle in four different embryos. Counts were performed in electroporated and control otic vesicles. The number of $\mathrm{pH} 3-$ positive cells was obtained for the whole otic vesicle and also for the electroporated domains. The number of $\mathrm{pH} 3$ cells within the electroporated domains was normalized to the surface of the electroporated areas and compared with an equivalent domain of the control side. This provides an estimate of the changes in cell proliferation rate independently of otic vesicle growth. Values were referred to controls that were arbitrarily set to one. Results are shown as average \pm SEM, and Student's $t$ test was used to assess statistical significance.

Immunohistochemistry. For immunohistochemistry, either cryostat or paraffin sections were prepared and processed using standard protocols. The following antibodies were used: Pax2 (PRB-276P), TuJ1 (MMS435P), and Prox1 (PRB-238C) from Covance; Sox2 (sc-17320), jag1 (sc6011), proliferating cell nuclear antigen (PCNA) (sc-7907), and Sox10 (sc-17342) from Santa Cruz Biotechnology; p27 ${ }^{\text {Kipl }}$ (RB-9019-P0) and cyclin D1 (RM-9104-S0) from Thermo Fisher Scientific; myosin VIIA (25-6790) from Proteus; calretinin (7699/3H) from Swant; p75 (AB1554) from Millipore; and Atoh1 (gift from Jane Johnson, Universtiy of Texas Southwestern Medical Center, Dallas, TX). Detection of cell proliferation was performed by immunohistochemistry using the antiphosphorylated histone $\mathrm{H} 3$ antibody (catalog \#06-570, rabbit polyclonal $\mathrm{pH} 3$; Millipore). An antigen retrieval step consisting of incubation in 1 mu sodium citrate and $0.005 \%$ Tween $20, \mathrm{pH} 6.0$, at $98^{\circ} \mathrm{C}$ for 20 min was required for the following antibodies: cyclin D1, PCNA, pH3, and Prox1 antibodies. For immunofluorescence, cryostat sections were incubated with primary antibodies, and the corresponding secondary antibodies used were goat anti-mouse Alex Fluor-488, donkey anti-goat Alexa Fluor-488, and goat anti-rabbit Alexa Fluor-568 or Alexa Fluor-488 (all from Invitrogen). Some of the sections were counterstained with DAPI. Whole-mount immunolabeling, dehydration, and clearing of inner ears was performed as described previously (MacDonald and Rubel, 2008). On paraffin sections, primary antibodies were detected with a biotinylated rabbit IgG using the $\mathrm{ABC}$ method (Vectastain kit; Vector Laboratories). TUNEL analysis was performed using an in situ cell death detection kit following the recommendations of the manufacturer (catalog \#11 684 795 001; Roche). Bright-field images were captured with a DFC 490 camera (Leica) on a Labophot-2 microscope (Nikon). Immunofluorescence images were taken with a Nikon Eclipse 80i fluorescence microscope, Bio-Rad Radiance 2000, or Leica SP confocal microscope and processed using Photoshop (Adobe Systems). For analysis of proliferation and cell death, cell counts were performed. For statistics, 10 sections of otic vesicles with similar dimensions and derived from three animals per group were selected, and differences were confirmed by Student's $t$ test.

Optical projection tomography. Embryos were fixed overnight in $4 \%$ paraformaldehyde at $4^{\circ} \mathrm{C}$, rinsed briefly in distilled water, and embedded in prewarmed low-melting agarose ( $1 \%$ in water). Once the agarose had solidified at room temperature, blocks were cut and dehydrated in methanol overnight. After dehydration of the agarose blocks, specimens were cleared in benzyl alcohol/benzyl benzoate (1:2) for 1 or $2 \mathrm{~d}$. Scans were performed in a bright-field channel using 700 or $750 \mathrm{~nm}$ filters. The 3D 
A

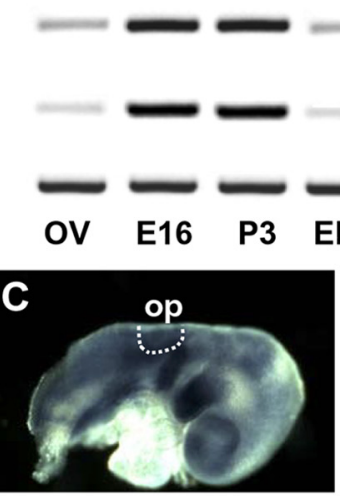

D
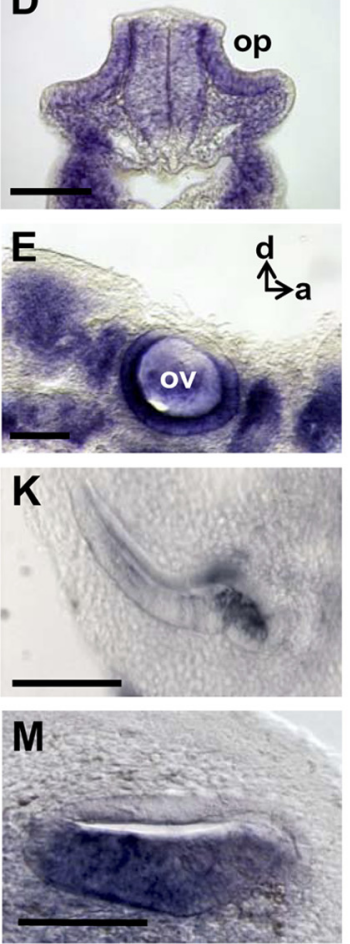
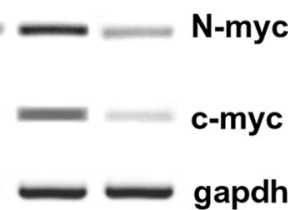

EP3 P10 adult
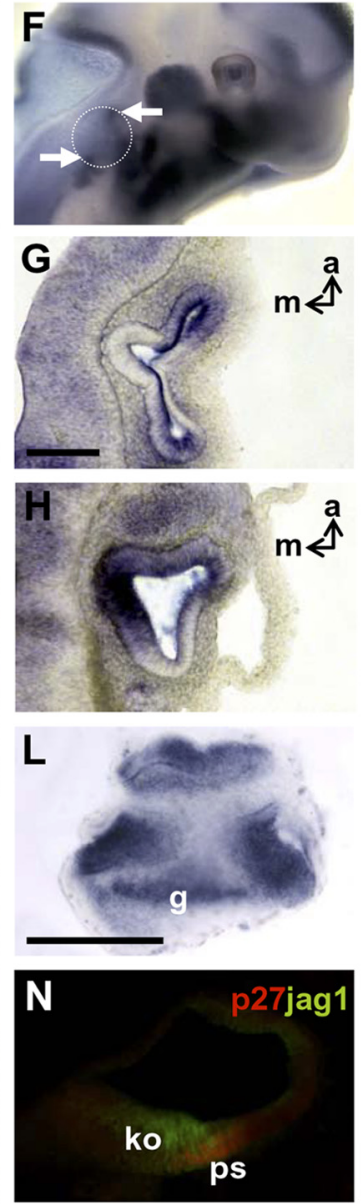

B
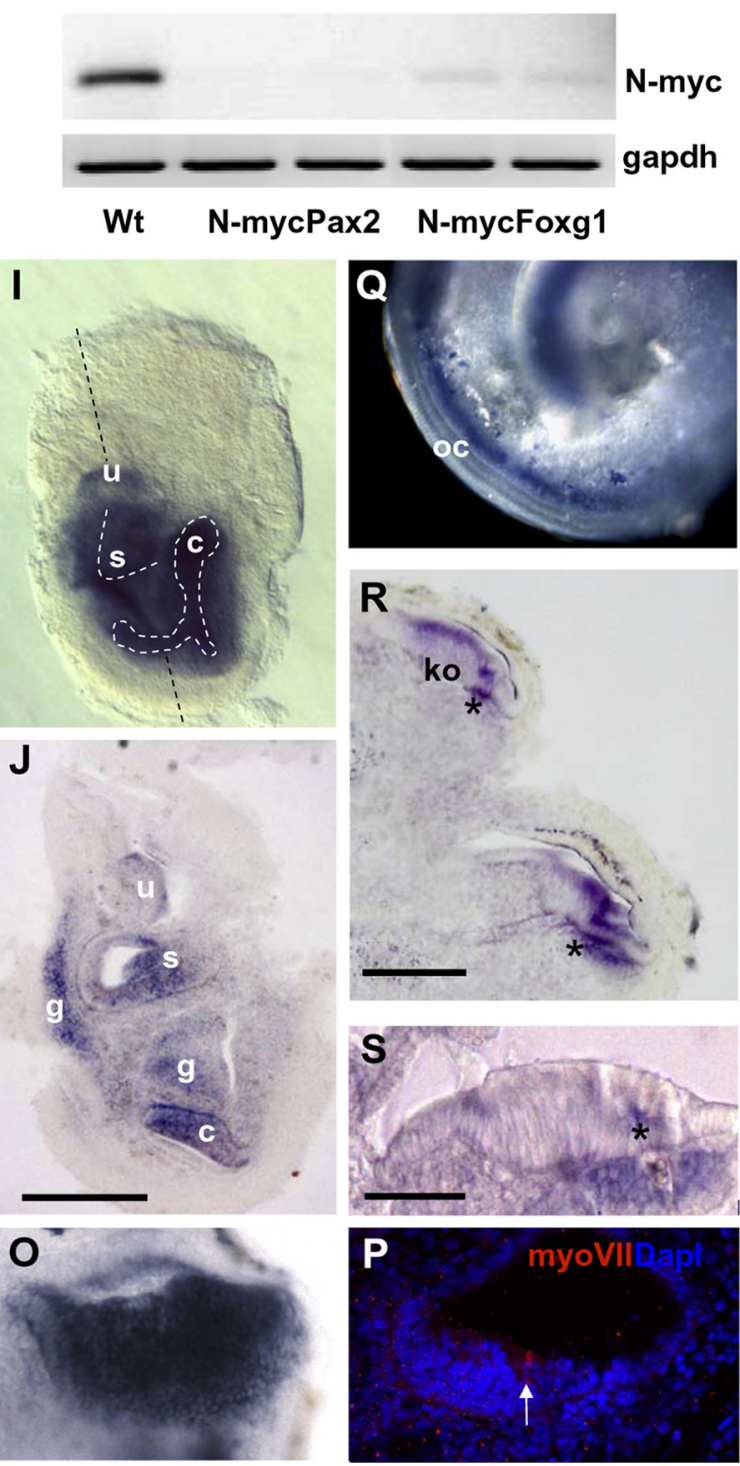

Figure 1. Expression and inactivation of $N$-myc in the inner ear. $A, R T-P C R$ for $N-m y c, c-m y c$, and gapdh as a control was conducted on total RNA isolated from otic vesicles (OV) isolated at E11, inner ears at E16, P3, P10, and adult stage, and cochlear sensory epithelia at P3 (EP3).B, RT-PCR for N-myc and gapdh as a control was performed on total RNA from inner ears at P0 from wild-type (Wt) and mutants in which $N$-myc has been inactivated by Cre driven by Foxg 1 or Pax2. C-S, Expression of $N$-myc detected by RNA in situ hybridization. C, D, At E8.5, N-myc is expressed in the otic placode (op) that is indicated by stippled lines in $\boldsymbol{C}$ and shown on a horizontal section in $\boldsymbol{D}$. $\boldsymbol{E}, 0$ n a sagittal section at E9.5, N-myc RNA is detected throughout the otic vesicle (ov) with exception of the dorsal portion. $\boldsymbol{F}, \boldsymbol{G}$, In otic vesicles at E11.5 (circumference indicated by stippled lines), $N$-mycis detected in the anterior (a) and posterior ( $\mathrm{p}$ ) prosensory patch (arrows) in a whole mount $(\boldsymbol{F})$ and on a horizontal section through the dorsal part of the vesicle (G). $\boldsymbol{H}$, Additionally, $\mathrm{N}$-myc is expressed in the medioventral part of the otic vesicle corresponding to the future prosensory region of the cochlea. Orientations of the sections through the otic vesides along the

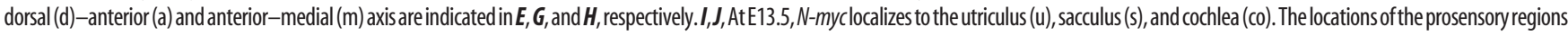
of the sacculus and cochlea and the level of the section shown in $J$ are indicated. Additional labeling corresponds to ganglia $(\mathrm{g})$ and nerve fibers innervating the prosensory regions. $L, M, 0, S e c t i o n s$ through the cochlea at E13.5 $(\boldsymbol{M})$ and E14.5 $(\boldsymbol{L}, \mathbf{0})$ reveals $N$-myc expression throughout the basal part of the cochlear duct. $\boldsymbol{N}, \boldsymbol{P}$, Localization of Kölliker's organ (ko), the prosensory region (ps), and differentiating hair cells (arrow) localized within the $N$-mycexpression domain is shown by labeling with antibodies againstjagged1, p27 ${ }^{\text {Kip } 1}$, and myosin VIIA (counterstained with DAPI), respectively. $K$, Expression of $N$-mycin a section through the posterior cristae atE14.5. Q, Expression of $N$-myc in isolated cochlear sensory epithelia at E18.5 is observed on the modiolar side of the organ of (orti (oc). $\boldsymbol{R}$, Sections through the cochlea reveals some remnants of $\mathrm{N}$-myc expression throughout Kölliker's organ (ko) in the apical turn. Higher levels of $N$-myc expression are maintained in nerve fibers (asterisks) that run beneath the sensory epithelium and innervate hair cells, shown at a higher magnification for a basal turn in $S$. Scale bars: $L, J, 200 \mu \mathrm{m} ; \boldsymbol{D}, \boldsymbol{E}, \mathbf{G}, \boldsymbol{K}, \boldsymbol{M}, \boldsymbol{R}, 100 \mu \mathrm{m} ; S, 50 \mu \mathrm{m}$.

reconstructions were performed as described (Sharpe et al., 2002). Images of virtual sections shown here were captured directly from the 3D reconstructions.

\section{Results}

Expression and inactivation of $m y c$ genes in the inner ear To study the functions of $m y c$ genes during inner ear development, we first analyzed the expression of $c-m y c$ and $N-m y c$, both of which have been shown to play essential roles during embryonic development and organogenesis (Hurlin, 2005; Eilers and
Eisenman, 2008). RT-PCR analysis demonstrated that $c-m y c$ and $N-m y c$ were coexpressed at approximately similar amounts throughout inner ear development (Fig. 1A). Weak expression was observed at early stages (otic vesicle stage), whereas highest levels of transcripts were observed in inner ears isolated at midembryogenesis and early postnatal stage. At the latter stage, we also confirmed expression in isolated sensory epithelia from the cochlea. Postnatally expression levels of $c-m y c$ and N-myc declined and were maintained at low levels in the adult inner ear. 
Because both $c-m y c$ and $N-m y c$ null mutants die during early inner ear development, we used a conditional approach to inactivate $m y c$ genes in the inner ear. Mouse mutants carrying floxed alleles for $c-m y c$ and $N-m y c$ (Trumpp et al., 2001; Knoepfler et al., 2002) were crossed with Cre lines driven by the Foxg1 locus or Pax2 regulatory sequences already successfully used to inactivate floxed alleles during the earliest stages of inner ear development (Pirvola et al., 2002; Ohyama and Groves, 2004). Inactivation of $N-m y c$ and $c-m y c$ was confirmed by RT-PCR using RNA isolated from neonatal inner ears. Whereas homozygous myc mouse mutants carrying Pax2Cre showed no expression of $m y c$ transcripts, some traces of $N-m y c$ and $c-m y c$ transcripts were still observed in the presence of Foxg1Cre (Fig. $1 B$ ). Phenotypic and immunohistological analysis of the inner of $c$-myc mutants showed no defects during inner ear development. In contrast, $N$-myc mutants exhibited a series of inner ear defects that were fully penetrant and will be described in the following sections. Correlating with the degree of conditional inactivation of $N-m y c$ as suggested by remaining transcript levels, $\operatorname{Pax} 2 \mathrm{Cre}-\mathrm{N}-m y c$ mutants showed a slightly more severe expressivity of the mutant phenotypes compared with Foxg1Cre-N-myc mutants. Throughout the text, we will refer to $N-m y c$ homozygous mutants created by Foxg1Cre or Pax2Cre as $N$ - myc mutants. The respective Cre line used to inactivate $N-m y c$ is indicated in the corresponding figures.

Because $N$-myc proved to be essential for inner ear development, we next examined the spatial expression pattern of $N-m y c$ in the inner ear. We thus analyzed the expression of $N-m y c$ by RNA in situ hybridization throughout inner ear development. $N$-myc was expressed in the invaginating otic placode at E8.5 (Fig. $1 C, D)$. During formation of the otic vesicle, $N$-myc expression was detected throughout the otic epithelium excluding its dorsal aspect (Fig. 1E). Next, $N-m y c$ expression concentrated in the anterior and posterior poles of the otic vesicle that correspond to the future prosensory regions of the vestibular part of the inner ear (Fig. $1 F, G$ ). Additional labeling was observed in the medioventral domain corresponding to the future prosensory region of the cochlea (Fig. 1H). During formation of the prosensory patches, $N$-myc was expressed in the utricle, saccule, and cochlea and also in the ganglia and the innervating nerve fibers (Fig. $1 I, J)$. At E14.5, $N$-myc expression was also observed in the cristae of the semicircular canals (Fig. $1 \mathrm{~K}$ ). A more detailed study of $N$-myc expression in the cochlea at these stages showed that $N$-myc was expressed throughout the basal region of the cochlear duct (Fig. $1 L, M, O$ ), part of which will form the prosensory domain that can be visualized by labeling with p27 $7^{\text {Kipl }}$ (Fig. $1 \mathrm{~N}$ ). Neighboring the prosensory region, the N-myc expression domain also included Kölliker's organ (KO), a transient structure that will form the inner sulcus and is labeled by jagged1 (Fig. $1 M, N) . N-m y c$ expression was maintained throughout the basal part of the cochlea during initiation of hair cell differentiation at E14 as evidenced by the onset of myosin VIIA expression in the basal part of the cochlea (Fig. 1O,P). In the differentiated cochlear duct, $N-m y c$ was downregulated with some remnants of expression maintained throughout $\mathrm{KO}$ in the apical part (Fig. 1Q,R). At this stage, strong $N$-myc expression was maintained in nerve fibers innervating hair cells (Fig. $1 R, S$ ).

\section{Inner ear defects in $N$ - myc mutants}

$N$-myc mutants were analyzed from the otic vesicle stage (E9) until adulthood. The diameter of the otic vesicle of homozygous $N$-myc mutants was reduced by $\sim 20 \%$ with respect to wild-type littermates (Fig. 2A). Homozygous Foxg1Cre-N-myc mutants died at birth or within the first postnatal days after birth and thus
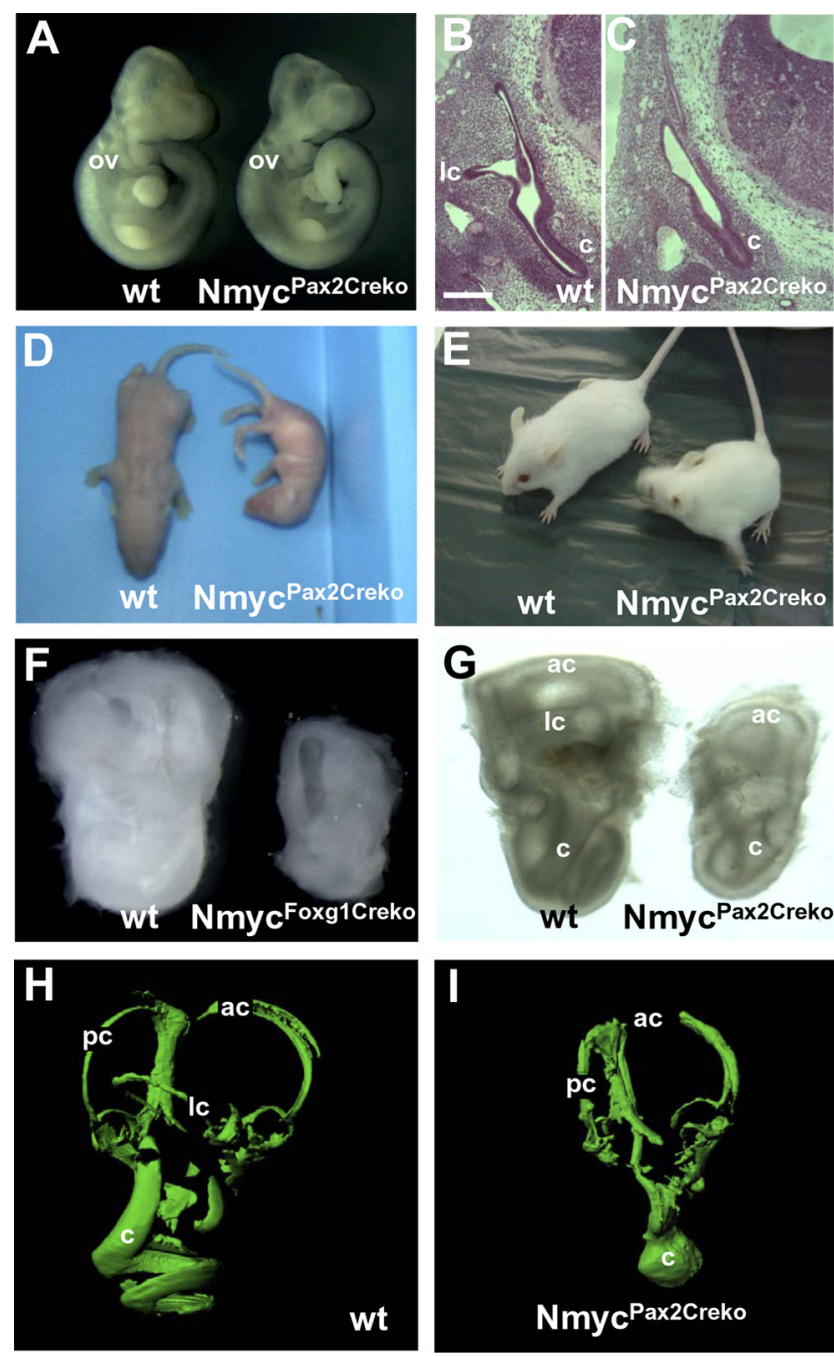

Figure 2. Inner ear phenotype of $N$-myc mutants. $\boldsymbol{A}$, Wild-type (wt) and Pax2Cre-N-myc mutant embryos at E10. The size of the otic (ov) is reduced in the mutant embryo. B, C, At E12.5, N-myc mutants show a shortened cochlear duct (c) and absence of the lateral semicircular canal (Ic). D, AtP2, Pax2Cre-N-myc mutants are smaller than their wild-type littermates and fail to assume an upright position. $\boldsymbol{E}$, Juvenile Pax2Cre-N-myc mutants show head bobbing and circling behavior. $\boldsymbol{F}, \boldsymbol{G}$, Isolated inner ears from Foxg 1 Cre-N-myc mutants at E16 and Pax 2 Cre-N-myc mutants at P2 are smaller compared with wild-type inner ears. Clearing of the specimens indicates a lack of the lateral canal and a shortened cochlea with a reduced coiling. $\boldsymbol{H}, \boldsymbol{I}, \mathrm{P} 2$ inner ears carrying a Pax2Cre transgene and a ROSA26 reporter were stained for lacZ and processed for optical projection tomography confirming the absence of the lateral canal. ac, Anterior canal; pc, posterior canal.

prevented the analysis of inner ear development beyond this stage. Pax 2 Cre $-N-m y c$ mutants were born alive, showed a reduced size compared with wild-type littermates, and failed to reach an upright position as neonates (Fig. 2D). As juveniles and adults, the Pax2Cre-N-myc mutants showed head bobbing and circling behavior, indicating an inner ear defect (Fig. 2E). A gross examination of inner ears isolated from $\mathrm{N}$-myc mutant animals revealed a reduced size compared with controls (Fig. 2F, G). Clearing of the specimens revealed a shortened cochlea with reduced coiling and indicated the absence of the lateral semicircular canal (Fig. 2G). The absence of the lateral semicircular canal was confirmed on histological sections at E12 (Fig. $2 B, C$ ). To verify this phenotype at the postnatal stage, we performed wholemount $\beta$-galactosidase staining of inner ears from animals that carried a ROSA26lacZ reporter (Soriano, 1999). The presence of Pax2Cre or Foxg1Cre that are active in the early otic vesicle allows 
labeling of inner ear components throughout development. Labeled inner ears were cleared and processed for optical projection tomography that allows a detailed reconstruction of the specimens (see Materials and Methods). While controls showed the presence of all three semicircular canals, in $N$-myc mutants, the horizontal canal was completely absent (Fig. $2 H, I$ ) (see Note added in proof).

\section{$N-m y c$ controls proliferation in the} otic vesicle

The smaller size of the otic vesicle observed in $N-m y c$ mutants may be caused in principle by a lack of proliferation, increased apoptosis, or both. To examine cell proliferation, we used staining with an antibody against $\mathrm{pH} 3$ that labels cells in late $\mathrm{G} 2$ and $\mathrm{M}$ phase of the cell cycle. Serial sections through the otic vesicle revealed a reduced number of cells stained with the pH3 antibody in the otic epithelium compared with wild-type embryos (Fig. $3 A, B)$. In contrast, proliferation in the surrounding mesenchyme appeared unaffected. Cells counts of $\mathrm{pH} 3$-positive cells revealed that cell proliferation was reduced by $\sim 50 \%$ ( $48 \pm 6$ cells vs $25 \pm 3$ cells; $n=10 ; p<0.0001)$ in the otic epithelium of $N-m y c$ mutants, which was also thinner when compared with controls (Fig. $3 A, B$ ). Proliferation was further examined in the developing cochlear duct at E13.5. At this stage, $\mathrm{pH} 3$-positive cells were detected in the region of Kölliker's organ in wild-type animals (Fig. 3C). In contrast, the basal part of the cochlear duct of N-myc mutants showed no proliferating cells (Fig. 3D).

To examine cell death, we used TUNEL staining. In serial sections through the otic vesicle, apoptotic cells were present in well known sites of cell death, such as the endolymphatic duct (Fekete et al., 1997), in both wild-type and $N-m y c$ mutants (Fig. $3 E, F)$. However, no increased or ectopic cell death was detected in otic vesicles of $N$-myc mutants, suggesting that apoptosis is not the cause of the observed reduced growth.

To further analyze the role of $N-m y c$ for cell proliferation in the inner ear, we performed gain-of-function experiments by misexpression of $N-m y c$ in chicken embryos. For this purpose, we electroporated a cDNA for $N-m y c$ together with a GFP reporter (see Materials and Methods) into the otic placode of chicken embryos. Six hours after electroporation, ectopic N-myc expression was confirmed by immunohistochemistry and colocalized with GFP expression (Fig. 3I). We then examined the size of otic vesicles and cell
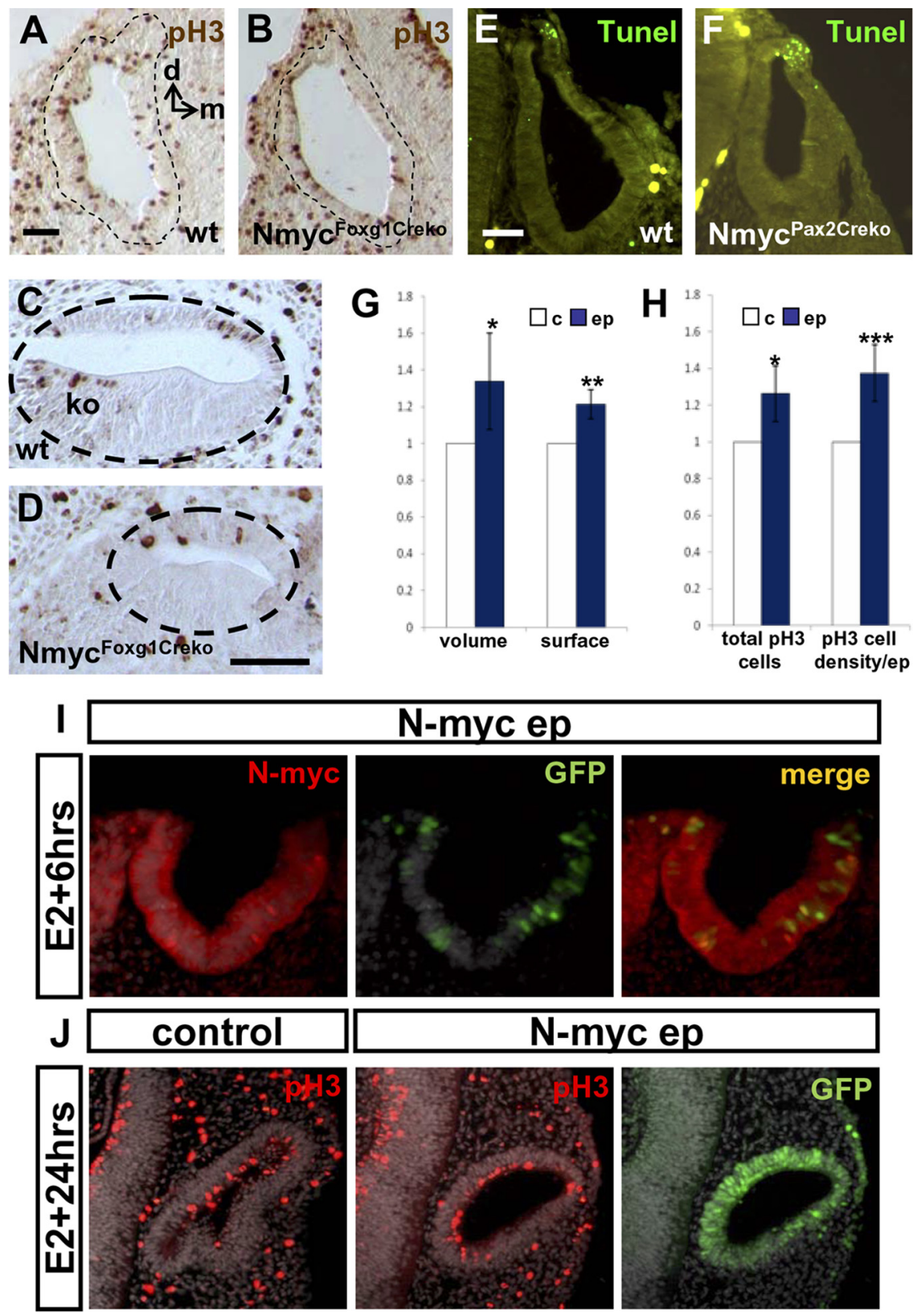

Figure 3. Effects of $N$-myc on proliferation and cell death during inner ear development. Sections through the inner ear of wild-type animals $(\boldsymbol{A}, \boldsymbol{C}, \boldsymbol{E})$ and $\mathrm{N}$-myc mutants $(\boldsymbol{B}, \boldsymbol{D}, \boldsymbol{F})$ were stained as indicated. $\boldsymbol{A}-\boldsymbol{D}$, Cell proliferation was examined by labeling sections with antibodies against $\mathrm{pH} 3$. On selected sections in which otic vesicles showed similar dimensions between control and mutant, the number of pH3-labeled cells and the thickness of the otic epithelium appears reduced in $N$-myc mutants $(\boldsymbol{B})$ compared with controls $(\boldsymbol{A})$. The circumference of the otic vesicle is indicated by stippled lines. $d$, Dorsal; $m$, medial; wt, wild type. $C, D$, Sections through the cochlear duct atE13.5 (circumference indicated by stippled lines) reveal the presence of pH3-positive cells in Kölliker's organ (ko) in wild-type embryos. N-myc mutants lack proliferating cells throughout the basal portion of the cochlear duct. $\boldsymbol{E}, \boldsymbol{F}$, Cell death was analyzed by TUNEL staining of the otic area. Apoptotic cells are present in the dorsal region of both wild-type and mutant vesicles. G, Bar charts indicating the volume and surface area of otic vesicles electroporated with $\mathrm{N}$-myc (ep) compared with control vesicles (c; set to 1 ). $\boldsymbol{H}$, The left bar chart indicates the total number of pH3-positive cells per otic vesicle. The right bar chart shows the density of pH3-positive cells in $\mathrm{N}$-myc-electroporated domains and in equivalent domains of control vesicles (c; set to 1). The error bars represent SEM. ${ }^{*} p<0.05$, ${ }^{* *} p<0.01$, and ${ }^{* * *} p<0.001$, levels of significance of the difference with respect to control values calculated by the Student's $t$ test. I, Sections from otic placodes $2 \mathrm{~h}$ after coelectroporation with vectors expressing $N$-myc and GFP. Cells electroporated with the vectors can be detected by antibodies against $\mathrm{N}$-myc and expression of GFP. J, Sections from otic vesicles labeled with antibodies against pH3 to detect proliferating cells. Proliferating cells are observed within the electroporated area. Note that the electroporated otic vesicles have not initiated morphogenesis as observed in controls. Scale bars: $A, D, E, 50 \mu \mathrm{m}$. proliferation $24 \mathrm{~h}$ after electroporation by serial reconstruction and labeling with $\mathrm{pH} 3$ antibodies (Fig. $3 J$ ). Volume and surface area were significantly increased in $N$-myc electroporated otic vesicles (Fig. $3 G$ ). In parallel, the number of $\mathrm{pH}$-positive 

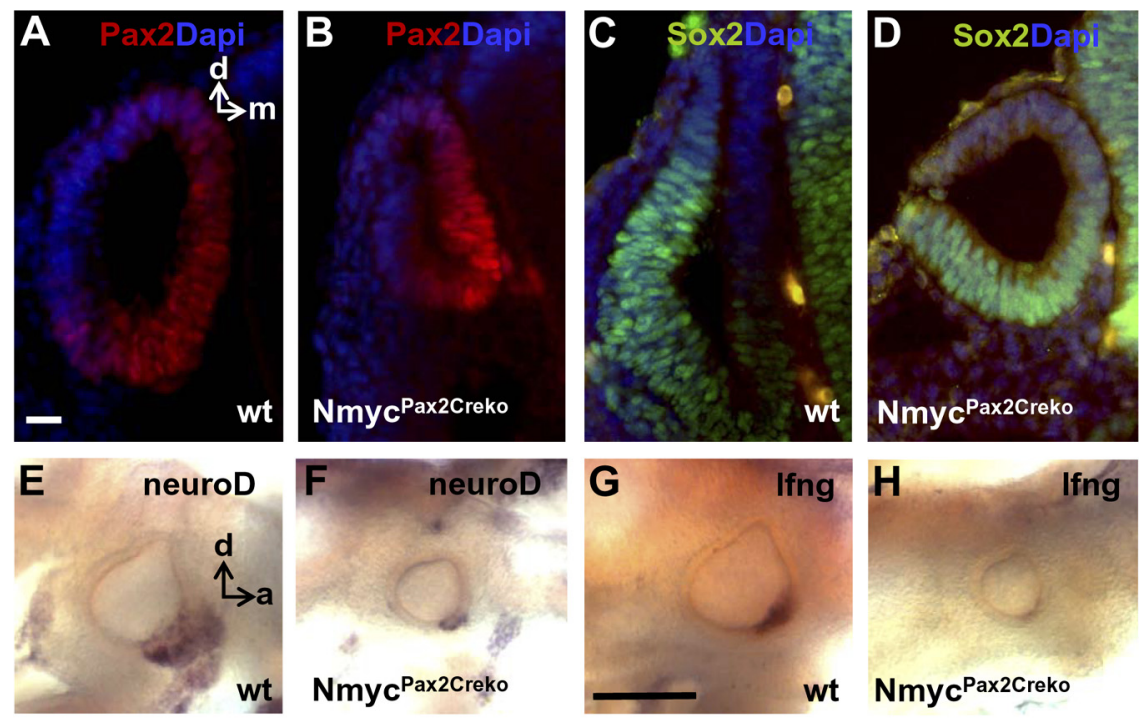

Nmyc Pax2Creko
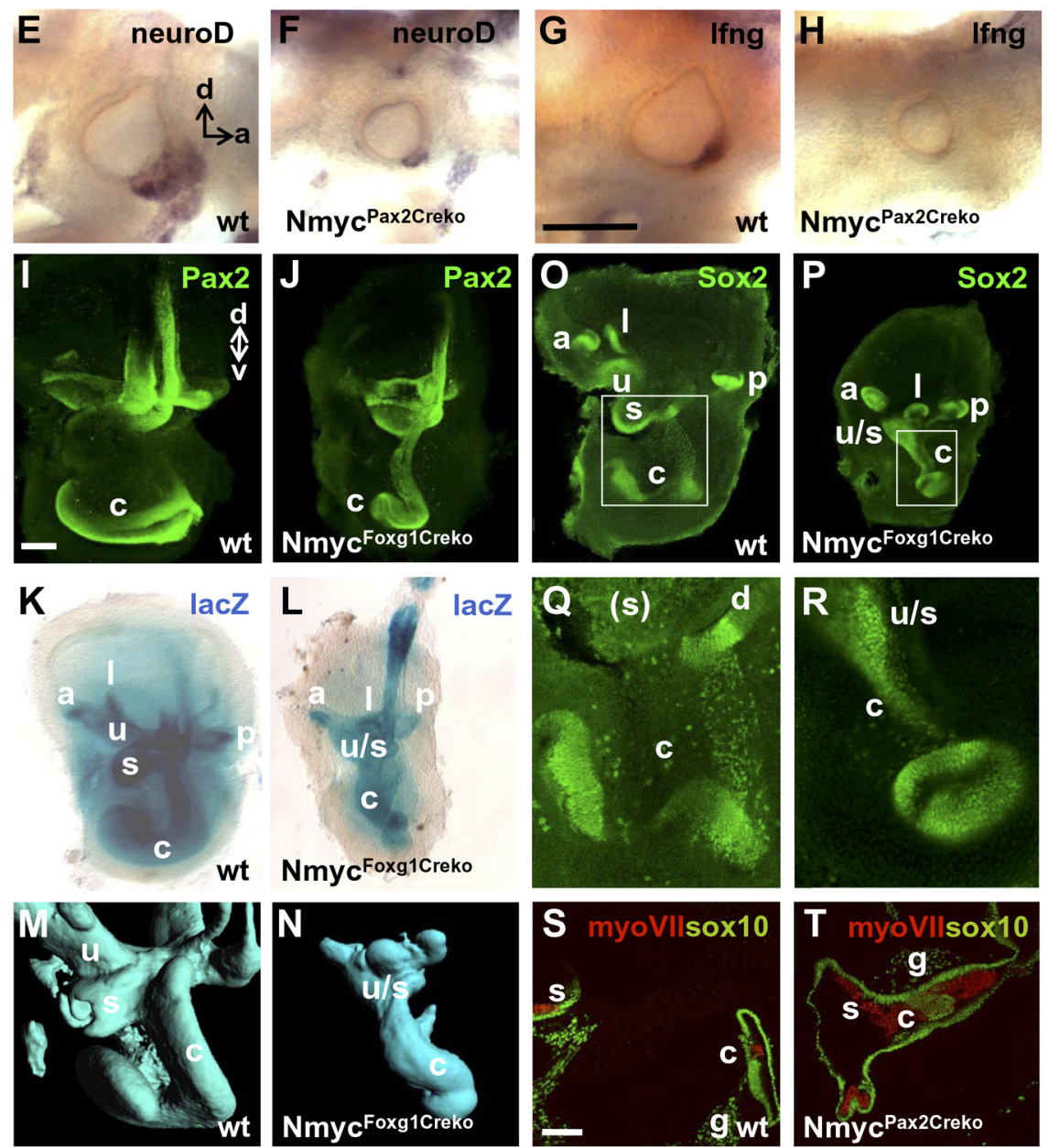

Figure 4. Expression of early otic markers, defective cochlear outgrowth, and fusion between sensory regions in $N$-myc mutants. $A-D$, Labeling of sections through the otic vesicle with Pax2 and Sox2 antibodies reveals normal expression of these markers in $N$-myc mutants. Sections were counterstained with DAPI. Orientation of sections along the dorsal (d)-medial (m) axis are indicated in $\boldsymbol{A}$. wt, Wild type. $\boldsymbol{E}-\boldsymbol{H}$, Hybridization with riboprobes for $L F n g$ and NeuroD reveals a correct localization of these genes within their normal expression domains in $\mathrm{N}$-myc mutants, although their intensity is reduced compared with the wild-type. Orientation of embryos along the dorsal (d)-anterior (a) axis are indicated in $\boldsymbol{E}$. I, J, Inner ears were labeled with Pax2 antibodies at E13.5 as whole mounts. The extension and coiling of the cochlea (c) is reduced in $N$-mycmutants. Orientation of inner ears along the dorsal (d)-ventral (v) axis is indicated in $I . K-N, E 13.5$ inner ears carrying a Pax2Cretransgene and a ROSA26 reporter werestained for lac $Z(K, L)$ and processed for optical projection tomography $(\boldsymbol{M}, \boldsymbol{N})$. The position of the cochlea, sacculus (s), and utriculus ( $\mathrm{u}$ ) and anterior (a), lateral (l), and posterior (p) cristae are indicated. $\mathbf{0}, \boldsymbol{P}$, Inner ears were labeled with Sox2 antibodies atE13 as whole mounts. In wild-type embryos, the prosensory regions of the cochlea (c), utricular (u), and saccular (s) maculae and anterior (a), lateral (I), and posterior (p) cristae are labeled. In N-myc mutants, the prosensory region of the reduced sized cochlea has fused with the saccular and utricular maculae. The position of the lateral cristae is displaced compared with the wild-type. $\mathbf{Q}, \boldsymbol{R}$ Magnified boxed areas from $\boldsymbol{O}$ and $\boldsymbol{P}$ show the prosensory region of the cochlea that is connected with the ductus reuniens ( $d$ ) in the wild type. The position of the sacculus that cannot be seen in this confocal plane is indicated. In the mutant, the cochlear prosensory region is fused to the maculae at its base and ends with a short turn forming a knob-like structure at the apex. S, $I$, Sections along the dorsoventral axis of an inner ear at E18 labeled with myosin VIIA and Sox10 antibodies. Whereas in the wild-type the saccular maculae and cochlea appear clearly separated, in the $\mathrm{N}$-myc mutant, a fusion of the sensory areas, characterized by myosin VIIA-positive hair cells, is observed. Scale bars: $\boldsymbol{A}, 50 \mu \mathrm{m} ; \mathbf{G}, 200 \mu \mathrm{m}$; (in I) I-L, O, P, $100 \mu \mathrm{m}$; S, $100 \mu \mathrm{m}$. g, Cochlear ganglion. cells was also higher in $\mathrm{N}-\mathrm{Myc}$ electroporated otic vesicles than in controls (Fig. 3H, left bar diagram). This effect was indeed related to a change in the cell proliferation rate, because the density of cells labeled by $\mathrm{pH} 3$ antibodies was significantly increased within the $\mathrm{N}$-mycelectroporated domains (Fig. $3 H$, right bar diagram). Interestingly, despite their bigger size, otic vesicles electroporated with $N$-myc often failed to initiate proper morphogenesis. Together, these data support a role for $N-m y c$ in the regulation of cell proliferation in the inner ear.

$N-m y c$ is required for cochlear outgrowth and the separation of prosensory regions

Morphogenesis of the otic vesicle leads to the ventral outgrowth of the cochlea. In histological sections through the developing cochlea at E12, we observed a reduced outgrowth of the cochlear duct in N-myc mutants (Fig. 2B,C). Pax2 null mouse mutants show a defective outgrowth of the cochlear duct (Burton et al., 2004). Thus, to further characterize the N-myc mutant cochlear phenotype, we analyzed the expression of Pax2 protein. During normal development, Pax2 antibodies label the medial wall of the otic vesicle from where the cochlear anlage derives and later on in the sensory and nonsensory regions of the cochlear duct (Lawoko-Kerali et al., 2002; Burton et al., 2004). The reduced sized $N-m y c$ mutant otic vesicles showed a normal expression of Pax2 in the medial domain. (Fig. 4A,B). In E13.5 whole-mount controls, Pax2 labeled the outgrowing cochlear duct, which had initiated its characteristic lateral turning around the dorsoventral axis (Fig. 4I). In contrast, Pax 2 labeling of $N-m y c$ mutants confirmed the shortening of the cochlear duct and presence of a very limited and short turn at the most apical part that resolved in a knob-like structure (Fig. $4 J$ ).

We next analyzed the potential roles of $N-m y c$ during the development of neural elements of the inner ear. The neurosensory region of the otic vesicle is characterized by neurogenic genes, such as NeuroD (Alsina et al., 2009; Fritzsch et al., 2010). Whole-mount in situ hybridization of wild-type embryos at E9 revealed the presence of mRNA encoding NeuroD in the anteroventral quadrant of the otic vesicle and in delaminating neurons that will form the otic ganglion (Fig. $4 E$ ). In the reduced sized otic vesicles of $N-m y c$ mutants, NeuroD expression was likewise localized in the neurogenic region of the otic vesicle. However, NeuroD was low or 
absent in the expression domain corresponding to the nascent otic ganglion (Fig. $4 F$ ), indicating a developmental delay in delamination and/or proliferative expansion of otic neuroblasts.

The formation of the prosensory region has been shown to be controlled by Notch signaling (Daudet and Lewis, 2005; Kiernan et al., 2006; Hartman et al., 2010; Pan et al., 2010; Neves et al., 2011). LFng is a component of the Notch signaling pathway, and, at the otic vesicle stage, it is present in a slightly larger domain compared with NeuroD that is believed to encompass the prospective organ of Corti and the maculae (Fig. 4G) (Morsli et al., 1998; Koo et al., 2009). Although clearly reduced, the LFng expression domain was maintained in $N-m y c$ mutant otic vesicles (Fig. $4 H$ ).

Sox2, an HMG transcription factor essential for the formation of inner ear sensory regions (Kiernan et al., 2005; Dabdoub et al., 2008; Neves et al., 2011), is first expressed in the proneural region of the otic vesicle (Fig. 4C) and later on in the prosensory region of all developing sensory epithelia, including the posterior, lateral, and anterior cristae, the utricular and saccular maculae, and the cochlea (Kiernan et al., 2005; Mak et al., 2009). A normal distribution of Sox 2 was confirmed in the otic vesicle of $N-m y c$ mutants (Fig. 4D). At E13, the prosensory regions of wild-type inner ears showed an intense labeling with Sox 2 antibodies in whole-mount preparations (Fig. 4O). In $N$-myc mutants, the anterior cristae was approximately localized in its normal position (Fig. 4P). In contrast, the lateral cristae that is usually found in close proximity to the anterior cristae was now positioned at a more medial location and closer to the posterior cristae. Furthermore, the lateral orientation of the prosensory region of the lateral cristae had shifted to a dorsal direction. Finally, analysis of the cochlear duct confirmed its shortening and the presence of a small apical turn followed by a knob-like structure with intense Sox2 staining in $N$-myc mutants (Fig. 4O-R).

The different sensory areas of the inner ear are normally separated by epithelial constrictions such as the ductus reuniens between the cochlea and the saccule or the utriculo-saccular foramen between the saccule and the utricle. Strikingly, the basal part of the cochlear prosensory region of the $N-m y c$ mutant was fused with the neighboring sacculus and utriculus (Fig. 4O-R). This phenotype was confirmed by tomography of $\beta$-galactosidasestained inner ears of animals carrying the ROSA26lac $Z$ reporter at E13 (Fig. $4 K-N$ ). Analysis of mutant sections at E18 revealed a widening of the basal part of the cochlea, forming a continuum with the saccular region and confirmed the loss of the ductus reuniens (Fig. $4 S, T)$. Also at this stage, a fusion between the sensory regions of the cochlea and sacculus, now characterized by hair cells expressing myosin VIIA, was verified.

\section{p27 expression and cell cycle exit is increased in $N-m y c$ mutants}

Within the prosensory region of the cochlea, cell cycle exit occurs in a temporal wave that initiates at E12 in the apex and reaches the base at E14. Expression of the cdki p2 ${ }^{\text {Kip } 1}$ defines the prosensory region and closely mirrors cell cycle withdrawal. Furthermore, p $27^{\text {Kip } 1}$ has been shown to be required for the formation of the correct number of postmitotic progenitors that give rise to hair cells and supporting cells (Chen and Segil, 1999; Lee et al., 2006). We examined $\mathrm{p} 27^{\mathrm{Kip} 1}$ expression in the cochlea during and after cell cycle exit between E12 and E16. Wild-type embryos showed p2 ${ }^{\text {Kip } 1}$ expression in the prosensory region (Fig. 5A) paralleled by cell cycle exit that established a zone of non-proliferating cells as shown by the absence of labeling of proliferating cells by PCNA (S-phase marker) (Fig. 5C) or pH3 (Fig. 5E).
In $\mathrm{N}$-myc mutants, the shortened mutant cochlea failed to undergo the typical turning observed in controls but had elongated mostly along the dorsal ventral axis and ended in a rounded thickening at the most apical tip of the cochlear duct (Fig. 5I,J). The shortened cochlear duct showed p $27^{\text {Kipl }}$ expression throughout the apical part of the cochlea (Fig. $5 B, K$ ). This increase of $\mathrm{p} 27^{\mathrm{Kip} 1}$ expression in the apex of $N-m y c$ mutants was even more apparent at E16 (Fig. 5P,Q). Labeling with PCNA and $\mathrm{pH} 3$ antibodies confirmed that the expression of $\mathrm{p} 27^{\mathrm{Kip} 1}$ was paralleled by cell cycle exit in the $N-m y c$ mutant (Fig. 5D,F).

Suppression of cyclin D1 in developing hair cells has been associated with their differentiation and the maintenance of their postmitotic state (Laine et al., 2010). As described previously, cyclin D1 is broadly expressed in the cochlear epithelium and only shows a weak downregulation in the prosensory region of the basal turn in which hair cells have initiated their differentiation (Laine et al., 2010) (Fig. 5L). In contrast, $N$-myc mutants showed a strong downregulation of cyclin D1 immunoreactivity throughout the cochlear epithelium, particularly prominent in the apical part of the cochlea (Fig. $5 L-O$ ).

After the establishment of the postmitotic domain, sensory cell differentiation is initiated in the base of the cochlea and is characterized by the expression of Atoh1, the transcription factor that has been found to be both necessary and sufficient for the production of hair cells in the inner ear (Bermingham et al., 1999; Chen et al., 2002; Woods et al., 2004). By E14.5, Atoh1 expression is initiated near the base of the cochlea in a single column of cells that will form the IHCs (Chen et al., 2002) (Fig. 5G). In contrast, in the $N$-myc mutant, an excess of Atoh1-expressing cells were detected in the basal region of the cochlea, indicating that an unusually high number of precursors developed as hair cells (Fig. $5 H$ ). However, no precocious staining of Atoh1 or myosin VIIA was observed in the apical regions of the cochlear duct, indicating that the basal-to-apical gradient of differentiation was nevertheless maintained in the $N-m y c$ mutant cochlea.

\section{Aberrant patterning of the organ of Corti in $N-m y c$ mutants} In the mammalian cochlea, sensory cell differentiation and patterning leads to the formation of the organ of Corti. Histological sections through the cochlea of wild-type animals at postnatal day $0(\mathrm{P} 0)$ revealed the typical organization of cochlear turns: one row of IHCs and three to four rows of OHCs (Fig. 6A, C). The organ of Corti is flanked by the $\mathrm{KO}$ on the modiolar side (Fig. $6 C$ ), whereas on the strial side, outer hair cells are flanked by a series of specialized supporting cells, including Hensen's and Claudius cells that will form the outer sulcus. In N-myc mutants, the ordered rows of IHCs and OHCs were replaced by long rows or clusters of cells with a hair-cell-like morphology (Fig. 6B,D). Most strikingly, on the modiolar side of the organ of Corti, we observed a complete absence of the KO. To define these defects at the molecular level, we examined the expression of several markers. At E18, we observed that clusters of hair-cell-like cells formed in the $N-m y c$ mutants were positive for the expression of myosin VIIA, indicating their differentiation (Fig. 6E-H). We next sought to identify the presence of specific subtypes of hair cells and used calretinin antibodies that label IHCs at P0 (Dechesne et al., 1994) (Fig. 6I). In N-myc mutants, calretinin labeled some of the cells within the cluster of hair cells, suggesting their differentiation toward the IHC fate (Fig. $6 \mathrm{~J}$ ).

Formation of hair cells in the organ of Corti is accompanied by the development of specialized sets of supporting cells. At P0, Sox 2 that initially shows expression throughout the organ of Corti becomes downregulated in differentiating hair cells, al- 

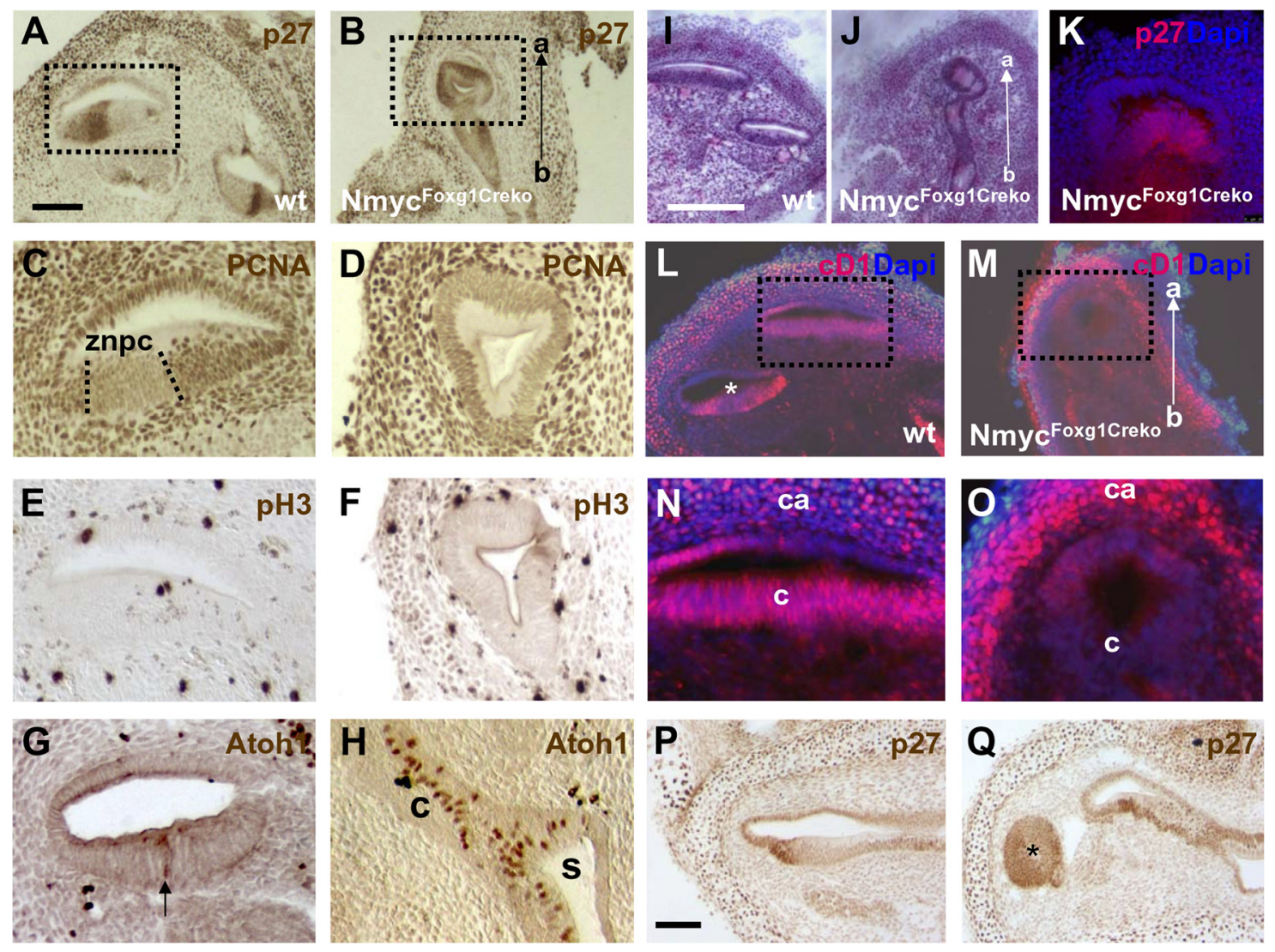

Figure 5. Cell cycle exit in $N$-myc mutants. Sections through the cochlea of wild-type animals $(\boldsymbol{A}, \boldsymbol{C}, \boldsymbol{E}, \boldsymbol{G}, \boldsymbol{L}, \boldsymbol{N}, \boldsymbol{P})$ and $N$-myc mutants $(\boldsymbol{B}, \boldsymbol{D}, \boldsymbol{F}, \boldsymbol{H}, \boldsymbol{K}, \boldsymbol{M}, \mathbf{O}, \mathbf{Q})$ were stained with the indicated antibodies. Expression of p $27^{\mathrm{Kip} 1}$ in the cochlear duct $(\boldsymbol{A})$ in a wild-type embryo at E14 defines the zone of non-proliferating cells (znpc) as shown by PCNA $(\boldsymbol{C})$ and pH3 $(\boldsymbol{E})$ staining (corresponding to the magnified boxed area from $\boldsymbol{A}$ in neighboring sections). In mutant $N$-myc embryos, the cochlea is reduced and expresses $p 27^{\text {kip1 }}$ throughout the apical part of the cochlear duct $(\boldsymbol{B})$, paralleled by a lack of PCNA (D) and pH3 (F) expression. $\mathbf{G}, \boldsymbol{H}$, In wild-type embryos, at E14, Atoh1 expression has been initiated in future inner hair cells (arrow). Note numerous cells expressing Atoh1 in the basal part of the cochlear duct in the mutant. c, Cochlea; S, sacculus. I,, , Histological sections at E14.5 reveals a shortened cochlear duct that fails to undergo appropriate coiling in the $N$-myc mutant. The basal (b)-apical (a) axis of the cochlea is indicated in $J . \boldsymbol{K}$, Expression of p27 ${ }^{\mathrm{Kip} 1}$ in the apical part of the cochlear duct in the $N$-myc mutant at E13. The section is counterstained with DAPI. $\boldsymbol{L}$, In wild-type animals at E14, cyclin D1 (CD1) is expressed throughout the basal part of the cochlear duct (c) with a slightly reduced staining in the prosensory region of the basal turn (asterisk). $M$, In $\mathrm{N}$-myc mutants, cyclin D1 is strongly downregulated in the apical part of the cochlear duct compared with controls, magnified in $\mathbf{N}$ and $\mathbf{O}$. Cartilage (ca) shows high cD1 expression in $N$-myc mutants. Sections were counterstained with DAPI. The orientation of the cochlea along the basal (b)-apical (axis) is indicated in $\mathbf{M} . \mathbf{P}, \mathbf{Q}$, Expression of p27 ${ }^{\text {Kip1 }}$ expression in the apical cochlear duct at E16.

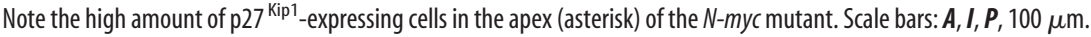

though it is maintained in supporting cells and in a group of cells within KO (Dabdoub et al., 2008). In wild-type animals, Sox2 labeling was observed in supporting cells, including the inner phalangeal cell, inner and outer pillar cells, Deiter's cells, and Hensen's cells, all of which were identified by their characteristic cell shape and position within the organ of Corti (Fig. $6 \mathrm{~K}$ ). In $\mathrm{N}$-myc mutants, Sox 2 labeling was reduced in cells underlying the myosin VIIA-positive hair cell clusters (Fig. $6 \mathrm{~L}$ ). Although these cells were likely to correspond to supporting cells, they could not be further classified into specific subtypes of supporting cells because of their rather homogenous shape and position within the mutant sensory epithelium. Some weak Sox2 labeling of cells was also observed in neighboring domains of the myosin VIIApositive cell clusters that may correspond to remnants of $\mathrm{KO}$ in the $N-m y c$ mutant.

To further try to identify the nature of the supporting cells in the $\mathrm{N}-m y c$ mutant, we next examined expression of Prox 1 and p75. At E18, Prox1 expression is normally observed in Deiter's and pillar cells (Bermingham-McDonogh et al., 2006; Kirjavainen et al., 2008) (Fig. 6M). In N-myc mutants, Prox1expressing cells were localized underneath hair cell rows also in $\mathrm{N}$-myc mutants (Fig. 6N). The low-affinity neurotrophin receptor $\mathrm{p} 75$ shows a highly characteristic pattern of expression in the apical and lateral cell membranes of the inner pillar cells and Claudius cells during differentiation of the organ of Corti ( $\mathrm{Mu}-$ eller et al., 2002; Shim et al., 2005) (Fig. 6O,Q). In the cell clusters present in the differentiating cochlear sensory epithelia of $N-m y c$ mutants, we observed elongated cells with a prominently labeling apical cell membrane resembling the so-called pillar cell head found in the inner pillar cell in controls (Fig. $6 P, R$ ). In the vicinity of these cells, we also found rows of smaller cells labeled with p75 that may correspond to groups of Claudius cells and that are usually found on the strial side of the organ of Corti. Cells that morphologically resembled Claudius and neighboring Hensen's cells could also be identified on histological sections in $N-m y c$ mutants (Fig. 6D).

Finally, we examined the innervation of the cochlear sensory epithelium in $\mathrm{N}-m y c$ mutants. Using different markers that label neuronal cell bodies or neurites such as TuJ1 (Fig. $6 E-H$ ), p75 (Fig. 6O,P), Sox2 (Fig. 6S,T), and Sox10 (Fig. 4S,T), we confirmed the presence of the cochlear ganglion and of nerve fibers that innervated the prosensory region or hair cells in $\mathrm{N}-\mathrm{myc}$ mutants.

In summary, different types of cells with a neuronal, hair cell, and supporting cell character are present in the differentiating cochlea of $\mathrm{N}-\mathrm{m} y \mathrm{c}$ mutants. However, within the organ of Corti, 

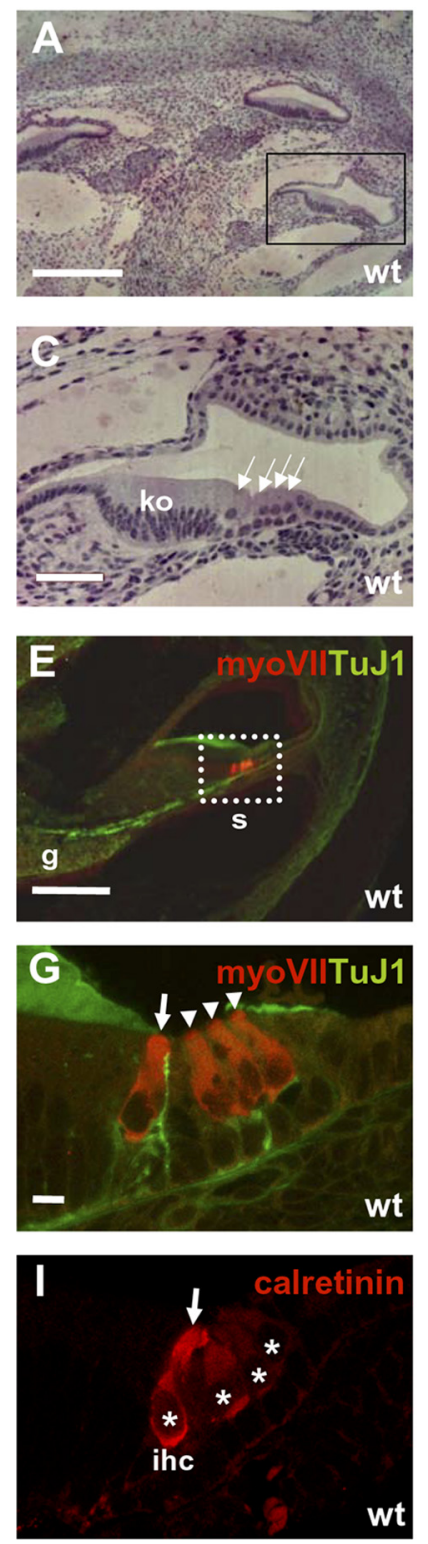
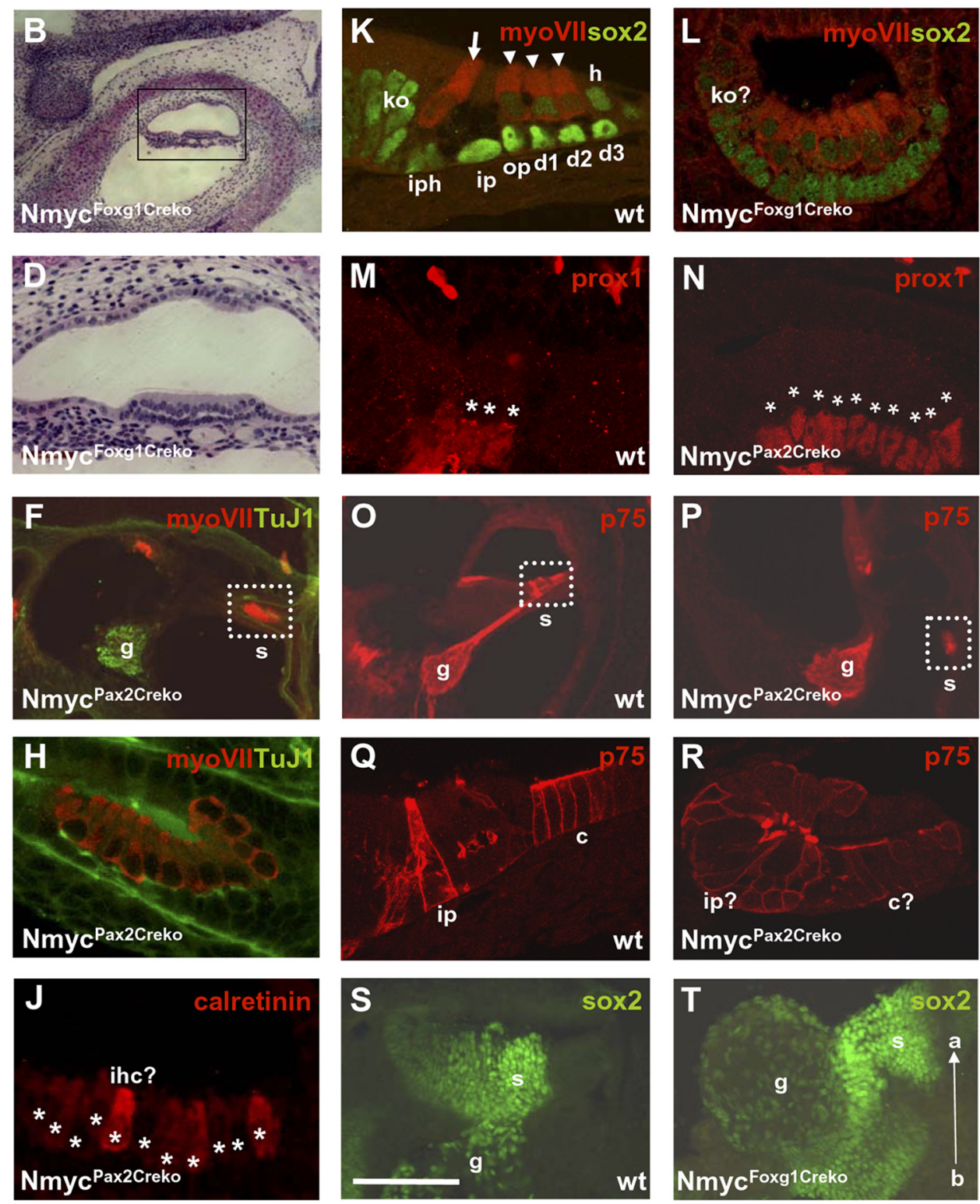

Figure 6. Differentiation of the cochlear sensory epithelium in $N$-myc mutants. $A, B$, Sections through the cochlea of a $N$-myc mutant at P0 reveal the presence of a cochlear duct (boxed area magnified in $\boldsymbol{C}, \boldsymbol{D}$ ) that fails to form the organ of Corti. Instead of one row of inner and three rows of outer hair cells (indicated by arrows) observed in the wild type (wt), a row of hair-cell-like cells is observed in $N$-myc mutants. Note the absence of Kölliker's organ (ko) in $N$-myc mutants. On the abneural side, the morphology of cells appeared similar between $N$-myc mutants and controls. $E-T$, Sections through the developing cochlear sensory epithelium of wild-type animals $(\boldsymbol{E}, \boldsymbol{G}, \boldsymbol{I}, \boldsymbol{K}, \boldsymbol{M}, \mathbf{O}, \mathbf{Q}, \mathbf{S})$ and $N$-myc mutants $(\boldsymbol{F}, \boldsymbol{H}, \boldsymbol{J}, \boldsymbol{L}, \boldsymbol{N}, \boldsymbol{P}, \boldsymbol{R}, \boldsymbol{T})$ stained with different antibodies as indicated. $\boldsymbol{E}$ - $\boldsymbol{H}$, Innervation of myosin VIIA (myoVII)-positive hair cells by $\beta$-tubulin (TuJ1)-labeled nerve fibers. The position of the cochlear ganglion (g) and the sensory epithelium (s; corresponding to the boxed area magnified in $\mathbf{G}$ and $\boldsymbol{H}$ ) is indicated. In $\boldsymbol{G}$, the inner hair cells (arrow) and outer hair cells (arrowheads) are indicated, whereas in the mutant, a cluster of hair cells is observed. $\boldsymbol{I}$, Staining with calretinin antibodies at PO labels the inner hair cell (ihc, arrow) in controls.J, Cells labeled with calretinin are also observed in a row of hair cells in the mutant. The position of cell nuclei are indicated by asterisks. $\boldsymbol{K}$, Staining with Sox2 antibodies in wild-type animals reveals the presence of Kölliker's organ (ko) and supporting cells, such as the inner phalangeal cell (iph), inner (ip) and outer (op) pillar cell, Deiter's cells (d), and Hensen's cells ( $h$ ). $L$, In the mutant, reduced Sox2 labeling is observed in cells underlying myosin VIIA-positive hair cells indicating the presence of supporting cells and some remnants of the neighboring Kölliker's organ. $\boldsymbol{M}, \boldsymbol{N}$, In wild-type embryos, Prox1 expression is found in supporting cells (pillar and Deiter's cells) underlying hair cells (indicated by asterisks). Prox1-expressing cells are detected underneath a hair cell cluster in $N$-myc mutants. $\mathbf{O}, \mathbf{P}$, Labeling with $\mathrm{p} 75$ antibodies shows the presence of the cochlear ganglion $(\mathrm{g})$ and of supporting cells within the sensory epithelium (s; boxes magnified in $\mathbf{Q}$ and $\boldsymbol{R}$ ). $\mathbf{Q}$, In the wild type, staining of the inner pillar cell (ip) and Claudius cells (c) is observed. $\boldsymbol{R}$, Labeling with p75 of a hair cell cluster indicates the presence of these cell types also in N-myc mutants. S, $\boldsymbol{T}$, Sox2 expression is found in the sensory epithelium (s) and the cochlear ganglion (g) at E14. The orientation of the cochlea along the basal (b)-apical (a) axis is indicated. Scale bars: $\boldsymbol{A}, \mathbf{S}, 100 \mu \mathrm{m}$; (in G) $\mathbf{G}-\mathbf{N}, \mathbf{Q}, \boldsymbol{R}, 50 \mu \mathrm{m}$; (in $\boldsymbol{E}) \boldsymbol{E}, \boldsymbol{F}, \mathbf{O}, \boldsymbol{P}, 100 \mu \mathrm{m}$.

the number and proportion of the different cell types and their complex topological organization is not established correctly.

\section{Discussion}

Myc proteins regulate fundamental cellular processes, such as proliferation, death, and differentiation in a variety of systems (Hurlin, 2005; Eilers and Eisenman, 2008). Generally, expression of $N$ - myc maintains cells in a proliferative state, and its downregulation often leads to differentiation (Hurlin, 2005). Consistent with this, we observed $N$-myc expression during proliferation in the otic placode and vesicle but not in differentiated hair cells. Cell proliferation was reduced in the otic vesicle of $\mathrm{N}-m y \mathrm{c}$ mutants and is therefore likely to cause reduced growth leading to a smaller inner ear. Additionally, the observed loss of proliferation in the basal part of the cochlear 
duct in $N$-myc mutants may cause the loss of Kölliker's organ and the lateral semicircular canal. The latter forms last during development and may be more vulnerable to a lack of proliferation (Rinkwitz et al., 2001). Similar proliferation and growth defects have been observed in the cerebellum, retina, and lung during loss of $N-m y c$ (Knoepfler et al., 2002; Okubo et al., 2005; Martins et al., 2008). However, in contrast to previous studies on lung and limb development, $N$-myc deficiency did not affect programmed cell death in the otic vesicle (Okubo et al., 2005; Ota et al., 2007).

In the vestibular system, the most apparent defect observed in $N$-myc mutants was the complete loss of the lateral canal. Of the mouse mutants with a vestibular phenotype reported to date, Otx1 (Morsli et al., 1999) and Shh (Riccomagno et al., 2002) mutants share the greatest similarity with the $N-m y c$ phenotype. All of these mutants show a specific loss of the lateral canal. Interestingly, in Shh mutants, loss of the lateral canal has been attributed to misexpression of Otx1 (Bok et al., 2007b). However, the $N-m y c$ mutant phenotype is unique because the lateral cristae, although displaced, is maintained, whereas it is absent in Otxl and Shh mutants.

Otxl mutants also share another feature in common with $N$-myc mutants, namely the fusion between different sensory epithelia. This phenotype manifests as a communication between the utricle and saccule via an open utriculo-saccular foramen and the absence of the ductus reuniens (Morsli et al., 1999; Fritzsch et al., 2001). In the $\operatorname{Lmx} 1$ mouse mutant, this phenotype is further exaggerated when compared with the Otx 1 mutant and leads to a closer proximity between the saccule and the base of the cochlea (Nichols et al., 2008). In the N-myc mutant, the most severe version of this phenotype is observed that consists in a complete fusion between the saccule, the utricle, and the base of the cochlea, with no apparent separation between the different sensory epithelia.

Several mouse mutants show a shortened cochlea that is associated with an excess of hair cells (Matei et al., 2005; Brooker et al., 2006; Kiernan et al., 2006; Pauley et al., 2006; Chen et al., 2008). Often this phenotype is most prevalent in the apical part of the cochlea, and this was also the case for the N-myc mutants reported here. This phenotype has been explained by various mechanisms, including the reduction in the number of sensory progenitors, earlier cell cycle exit, and a failure of convergent extension required for normal patterning of the organ of Corti. In the case of the $N-m y c$ mutant, the neurosensory region initially appears smaller, most likely because of the reduced growth rate and associated developmental delay of the otic vesicle. Next, the prosensory domain is specified in the mutant cochlea, but its outgrowth and coiling is severely affected. As judged by $\mathrm{p} 27^{\text {Kip } 1}$ and Sox 2 expression, the relative expansion of the prosensory region in the $N-m y c$ mutant is best observed in the apical part of the cochlea and near the fused saccular and utricular compartments. However, because of the overall reduction in size and the complex morphogenetic changes, it is difficult to assess the extent of the expansion of the prosensory region compared with the wild-type cochlea. Nevertheless, the mutant cochlea shows a clear increase in the number of cells expressing p2 $7^{\text {Kip } 1}$ and lacking cyclin D1 together with an expanded domain of cell cycle exit, particularly in the apical part. Because cyclins and cdkis are prime targets to coordinate proliferation with differentiation (Kwan et al., 2009) and both cyclinD1 and p $27^{\text {Kip } 1}$ have been postulated as targets of $N-m y c$ (Oliver et al., 2003), their dysregulation is likely to be directly responsible for the phenotype observed in the mutant cochlea. It is well documented that cdki p $27^{\text {Kipl }}$ is expressed in a temporal wave within the prosensory region that reflects the spatial and temporal pattern of cell cycle exit (Lee et al., 2006). $\mathrm{N}$-myc mutants maintain the normal onset of $\mathrm{p} 27^{\text {Kip } 1}$ expression in the apical part of the cochlea. However, the relative number of cells exiting the cell cycle in the cochlear duct appears increased when compared with wild-type animals. This is especially apparent in the apex in which essentially all cells express p $27^{\mathrm{Kip} 1}$ and exit the cell cycle. Therefore, our work indicates that N-myc usually represses directly or indirectly $\mathrm{p} 27^{\mathrm{Kip} 1}$ expression and prevents cell cycle exit and differentiation. In the case of the myc family member c-myc, this regulation may occur by direct binding to the p2 $7^{\mathrm{Kip} 1}$ promoter (Yang et al., 2001; Cowling et al., 2006). In parallel with the increase of $\mathrm{p} 27^{\mathrm{Kip} 1}$ expression, we also observed a decrease in the number of cells expressing cyclin D1. Normally, cyclin D1 is widely expressed in the cochlear epithelium, including the prosensory region, but is subsequently downregulated during differentiation of hair cells (Laine et al., 2010). Interestingly, D-type cyclins have been suggested to sequester cdkis, such as p $27^{\text {Kip } 1}$, thereby allowing downstream activation of cyclin complexes that promote cell cycle progression (Besson et al., 2008). Loss of cyclin D1 in the cochlear epithelium in N-myc mutants thus may lead to an increased availability of p $27^{\mathrm{Kip} 1}$, further promoting cell cycle exit and differentiation. Increased expression of $\mathrm{p} 27^{\mathrm{Kip} 1}$ and decreased cyclin D2, an additional $\mathrm{N}$-myc target, has also been observed in the cerebellum of mouse mutants lacking $N-m y c$ (Knoepfler et al., 2002). Similar to the cochlea, this dysregulation is paralleled by a loss of proliferation and the concomitant increase of postmitotic progenitors. Additionally, increased cell cycle exit is not followed by a precocious differentiation of neuronal progenitors. Repression of $\mathrm{p} 27^{\mathrm{Kip} 1}$ by $\mathrm{N}$-myc is also observed in retinal progenitor cells (Martins et al., 2008). Loss of $N-m y c$ in these cells leads to upregulation of $\mathrm{p} 27^{\mathrm{Kip} 1}$ and reduced proliferation. Interestingly in this case, although retinal progenitor cell proliferation is reduced, the hypocellular retina is properly proportioned to the other ocular structures. Thus, cell fate specification and differentiation is maintained and ensures the correct proportions of different retinal cell types. Similarly in the cochlea, our molecular analysis showed that different subtypes of hair and supporting cells are present in the absence of $N-m y c$. However, the correct proportions of the different cell types required for the formation of the organ of Corti are not maintained. Instead, there is an increase in the number of hair cells indicating a larger proportion of precursors that differentiate into this cell type. Because of the complex morphogenetic changes in the mutant cochlear duct, it is difficult to quantify the overall increase of sensory hair cells versus nonsensory cells. However, clearly in the apex, the vast majority of cells exit the cell cycle and differentiate into hair cells. As mentioned above, $N$-myc has been associated with increased differentiation in the cerebellum (Knoepfler et al., 2002), but this is not the case in other tissues, such as retina or lung (Knoepfler et al., 2002; Okubo et al., 2005; Martins et al., 2008). Concerning differentiation, $N-m y c$ thus acts in a context-dependent manner in different organs.

$\mathrm{N}$-myc is a member of the basic helix-loop-helix (bHLH) family of transcription factors, and different bHLH proteins have been postulated to form inhibitory loops among each other by competing for binding to the E box in their target genes (Fritzsch et al., 2010). In this context, Atoh1, which has been shown to be sufficient for the generation of ectopic hair cells in the cochlear sensory epithelium (Zheng and Gao, 2000; Woods et al., 2004), may be one of the bHLH factors that competes with N-myc during hair cell differentiation. Expression of N-myc in the prosensory region may normally counteract Atoh1, and, therefore, in 
the absence of $\mathrm{N}$-myc, an increase in the binding of Atoh1 to its target genes will thus promote cells to choose a hair cell fate.

An alternative source for additional hair cells found in the cochlear sensory epithelium of $N-m y c$ mutants may be KO. It has been shown previously that the $\mathrm{KO}$ is competent to generate ectopic hair cells, suggesting that $\mathrm{KO}$ may originate from an extended prosensory domain that becomes restricted during development (Zheng and Gao, 2000; Woods et al., 2004). Because KO is severely reduced or absent in N-myc mutants, it is tempting to speculate that some or all of the cells with a hair-cell-forming potential normally present in the $\mathrm{KO}$ region have been converted into hair cells.

Finally, it is worthwhile mentioning that heterozygous $N-m y c$ mutations are responsible for Feingold syndrome in humans (van Bokhoven et al., 2005). Feingold syndrome is a dominantly inherited disease characterized by microcephaly, cardiac defects, and facial deformities, among others. At a lower frequency, deafness of patients also has been reported (Marcelis et al., 2008). Therefore, additional studies on how $N-m y c$ controls cell proliferation, differentiation, and patterning in the inner ear will be vital to identify the molecular basis of human deafness.

Note added in proof. Similar and complementary findings on the postnatal inner ear phenotype of $N-m y c$ mutants are reported by Kopecky et al. (2011).

\section{Notes}

Supplemental material for this article is available at www. ibgm.med.uva.es/schimmang/index.html. Movie 1 shows a control P2 inner ear carrying a Pax2Cre transgene, and a ROSA26 reporter stained for lacZ and processed for optical projection tomography. Movie 2 shows a P2 N-myc mutant inner ear carrying a Pax2Cre transgene, and a ROSA26 reporter stained for $l a c Z$ and processed for optical projection tomography confirming the absence of the lateral canal. This material has not been peer reviewed.

\section{References}

Alsina B, Giraldez F, Pujades C (2009) Patterning and cell fate in ear development. Int J Dev Biol 53:1503-1513.

Alvarez Y, Alonso MT, Vendrell V, Zelarayan LC, Chamero P, Theil T, Bösl MR, Kato S, Maconochie M, Riethmacher D, Schimmang T (2003) Requirements for FGF3 and FGF10 during inner ear formation. Development 130:6329-6338.

Bermingham NA, Hassan BA, Price SD, Vollrath MA, Ben-Arie N, Eatock RA, Bellen HJ, Lysakowski A, Zoghbi HY (1999) Math1: an essential gene for the generation of inner ear hair cells. Science 284:1837-1841.

Bermingham-McDonogh O, Oesterle EC, Stone JS, Hume CR, Huynh HM, Hayashi T (2006) Expression of Proxl during mouse cochlear development. J Comp Neurol 496:172-186.

Besson A, Dowdy SF, Roberts JM (2008) CDK inhibitors: cell cycle regulators and beyond. Dev Cell 14:159-169.

Bok J, Chang W, Wu DK (2007a) Patterning and morphogenesis of the vertebrate inner ear. Int J Dev Biol 51:521-533.

Bok J, Dolson DK, Hill P, Rüther U, Epstein DJ, Wu DK (2007b) Opposing gradients of Gli repressor and activators mediate Shh signaling along the dorsoventral axis of the inner ear. Development 134:1713-1722.

Brooker R, Hozumi K, Lewis J (2006) Notch ligands with contrasting functions: Jagged 1 and Deltal in the mouse inner ear. Development 133:1277-1286.

Burton Q, Cole LK, Mulheisen M, Chang W, Wu DK (2004) The role of Pax2 in mouse inner ear development. Dev Biol 272:161-175.

Chen P, Segil N (1999) p27(Kip1) links cell proliferation to morphogenesis in the developing organ of Corti. Development 126:1581-1590.

Chen P, Johnson JE, Zoghbi HY, Segil N (2002) The role of Math1 in inner ear development: uncoupling the establishment of the sensory primordium from hair cell fate determination. Development 129:2495-2505.

Chen Z, Montcouquiol M, Calderon R, Jenkins NA, Copeland NG, Kelley
MW, Noben-Trauth K (2008) Jxc1/Sobp, encoding a nuclear zinc finger protein, is critical for cochlear growth, cell fate, and patterning of the organ of Corti. J Neurosci 28:6633-6641.

Cowling VH, Chandriani S, Whitfield ML, Cole MD (2006) A conserved Myc protein domain, MBIV, regulates DNA binding, apoptosis, transformation, and G2 arrest. Mol Cell Biol 26:4226-4239.

Dabdoub A, Puligilla C, Jones JM, Fritzsch B, Cheah KS, Pevny LH, Kelley MW (2008) Sox2 signaling in prosensory domain specification and subsequent hair cell differentiation in the developing cochlea. Proc Natl Acad Sci U S A 105:18396-18401.

Daudet N, Lewis J (2005) Two contrasting roles for Notch activity in chick inner ear development: specification of prosensory patches and lateral inhibition of hair-cell differentiation. Development 132:541-551.

Dechesne CJ, Rabejac D, Desmadryl G (1994) Development of calretinin immunoreactivity in the mouse inner ear. J Comp Neurol 346:517-529.

Eilers M, Eisenman RN (2008) Myc's broad reach. Genes Dev 22:2755-2766.

Fekete DM, Homburger SA, Waring MT, Riedl AE, Garcia LF (1997) Involvement of programmed cell death in morphogenesis of the vertebrate inner ear. Development 124:2451-2461.

Fritzsch B, Signore M, Simeone A (2001) Otx1 null mutant mice show partial segregation of sensory epithelia comparable to lamprey ears. Dev Genes Evol 211:388-396.

Fritzsch B, Eberl DF, Beisel KW (2010) The role of bHLH genes in ear development and evolution: revisiting a 10-year-old hypothesis. Cell Mol Life Sci 67:3089-3099.

Hamburger V, Hamilton HL (1992) A series of normal stages in the development of the chick embryo. 1951. Dev Dyn 195:231-272.

Hartman BH, Reh TA, Bermingham-McDonogh O (2010) Notch signaling specifies prosensory domains via lateral induction in the developing mammalian inner ear. Proc Natl Acad Sci U S A 107:15792-15797.

Hatton KS, Mahon K, Chin L, Chiu FC, Lee HW, Peng D, Morgenbesser SD, Horner J, DePinho RA (1996) Expression and activity of L-Myc in normal mouse development. Mol Cell Biol 16:1794-1804.

Hébert JM, McConnell SK (2000) Targeting of cre to the Foxg1 (BF-1) locus mediates loxP recombination in the telencephalon and other developing head structures. Dev Biol 222:296-306.

Hurlin PJ (2005) N-Myc functions in transcription and development. Birth Defects Res C Embryo Today 75:340-352.

Kelley MW (2006) Regulation of cell fate in the sensory epithelia of the inner ear. Nat Rev Neurosci 7:837-849.

Kelly MC, Chen P (2009) Development of form and function in the mammalian cochlea. Curr Opin Neurobiol 19:395-401.

Kiernan AE, Pelling AL, Leung KK, Tang AS, Bell DM, Tease C, Lovell-Badge $\mathrm{R}$, Steel KP, Cheah KS (2005) Sox2 is required for sensory organ development in the mammalian inner ear. Nature 434:1031-1035.

Kiernan AE, Xu J, Gridley T (2006) The Notch ligand JAG1 is required for sensory progenitor development in the mammalian inner ear. PLoS Genet 2:e4

Kirjavainen A, Sulg M, Heyd F, Alitalo K, Ylä-Herttuala S, Möröy T, Petrova TV, Pirvola U (2008) Proxl interacts with Atohl and Gfil, and regulates cellular differentiation in the inner ear sensory epithelia. Dev Biol 322:33-45.

Knoepfler PS, Cheng PF, Eisenman RN (2002) N-myc is essential during neurogenesis for the rapid expansion of progenitor cell populations and the inhibition of neuronal differentiation. Genes Dev 16:2699-2712.

Koo SK, Hill JK, Hwang CH, Lin ZS, Millen KJ, Wu DK (2009) Lmxla maintains proper neurogenic, sensory, and non-sensory domains in the mammalian inner ear. Dev Biol 333:14-25.

Kopecky B, Santi P, Johnson S, Schmitz H, Fritzsch B (2011) Conditional deletion of $\mathrm{N}$-myc disrupts neurosensory and non-sensory development of the ear. Dev Dyn. Advanced online publication. Retrieved April 19, 2011. doi:10.1002/dvdy.22620.

Kwan T, White PM, Segil N (2009) Development and regeneration of the inner ear. Ann N Y Acad Sci 1170:28-33.

Laine H, Sulg M, Kirjavainen A, Pirvola U (2010) Cell cycle regulation in the inner ear sensory epithelia: role of cyclin D1 and cyclin-dependent kinase inhibitors. Dev Biol 337:134-146.

Lawoko-Kerali G, Rivolta MN, Holley M (2002) Expression of the transcription factors GATA3 and Pax2 during development of the mammalian inner ear. J Comp Neurol 442:378-391.

Lee YS, Liu F, Segil N (2006) A morphogenetic wave of p27Kip1 transcrip- 
tion directs cell cycle exit during organ of Corti development. Development 133:2817-2826.

MacDonald GH, Rubel EW (2008) Three-dimensional imaging of the intact mouse cochlea by fluorescent laser scanning confocal microscopy. Hear Res 243:1-10.

Mak AC, Szeto IY, Fritzsch B, Cheah KS (2009) Differential and overlapping expression pattern of SOX2 and SOX9 in inner ear development. Gene Expr Patterns 9:444-453.

Marcelis CL, Hol FA, Graham GE, Rieu PN, Kellermayer R, Meijer RP, Lugtenberg D, Scheffer H, van Bokhoven H, Brunner HG, de Brouwer AP (2008) Genotype-phenotype correlations in MYCN-related Feingold syndrome. Hum Mutat 29:1125-1132.

Martins RA, Zindy F, Donovan S, Zhang J, Pounds S, Wey A, Knoepfler PS, Eisenman RN, Roussel MF, Dyer MA (2008) N-myc coordinates retinal growth with eye size during mouse development. Genes Dev 22:179-193.

Matei V, Pauley S, Kaing S, Rowitch D, Beisel KW, Morris K, Feng F, Jones K, Lee J, Fritzsch B (2005) Smaller inner ear sensory epithelia in Neurog 1 null mice are related to earlier hair cell cycle exit. Dev Dyn 234:633-650.

Morsli H, Choo D, Ryan A, Johnson R, Wu DK (1998) Development of the mouse inner ear and origin of its sensory organs. J Neurosci 18:3327-3335.

Morsli H, Tuorto F, Choo D, Postiglione MP, Simeone A, Wu DK (1999) Otx1 and Otx2 activities are required for the normal development of the mouse inner ear. Development 126:2335-2343.

Mueller KL, Jacques BE, Kelley MW (2002) Fibroblast growth factor signaling regulates pillar cell development in the organ of Corti. J Neurosci 22:9368-9377.

Neves J, Parada C, Chamizo M, Giráldez F (2011) Jagged 1 regulates the restriction of Sox2 expression in the developing chicken inner ear: a mechanism for sensory organ specification. Development 138:735-744.

Nichols DH, Pauley S, Jahan I, Beisel KW, Millen KJ, Fritzsch B (2008) Lmxla is required for segregation of sensory epithelia and normal ear histogenesis and morphogenesis. Cell Tissue Res 334:339-358.

Ohyama T, Groves AK (2004) Generation of Pax2-Cre mice by modification of a Pax2 bacterial artificial chromosome. Genesis 38:195-199.

Okubo T, Knoepfler PS, Eisenman RN, Hogan BL (2005) Nmyc plays an essential role during lung development as a dosage-sensitive regulator of progenitor cell proliferation and differentiation. Development 132:1363-1374.

Oliver TG, Grasfeder LL, Carroll AL, Kaiser C, Gillingham CL, Lin SM, Wickramasinghe R, Scott MP, Wechsler-Reya RJ (2003) Transcriptional profiling of the Sonic hedgehog response: a critical role for $\mathrm{N}$-myc in proliferation of neuronal precursors. Proc Natl Acad Sci U S A 100:7331-7336.

Ota S, Zhou ZQ, Keene DR, Knoepfler P, Hurlin PJ (2007) Activities of $\mathrm{N}-\mathrm{Myc}$ in the developing limb link control of skeletal size with digit separation. Development 134:1583-1592.

Pan W, Jin Y, Stanger B, Kiernan AE (2010) Notch signaling is required for the generation of hair cells and supporting cells in the mammalian inner ear. Proc Natl Acad Sci U S A 107:15798-15803.

Pauley S, Lai E, Fritzsch B (2006) Foxg1 is required for morphogenesis and histogenesis of the mammalian inner ear. Dev Dyn 235:2470-2482.

Pirvola U, Ylikoski J, Trokovic R, Hébert JM, McConnell SK, Partanen J (2002) FGFR1 is required for the development of the auditory sensory epithelium. Neuron 35:671-680.

Riccomagno MM, Martinu L, Mulheisen M, Wu DK, Epstein DJ (2002) Specification of the mammalian cochlea is dependent on Sonic hedgehog. Genes Dev 16:2365-2378.

Rinkwitz S, Bober E, Baker R (2001) Development of the vertebrate inner ear. Ann N Y Acad Sci 942:1-14.

Sawai S, Shimono A, Wakamatsu Y, Palmes C, Hanaoka K, Kondoh H (1993) Defects of embryonic organogenesis resulting from targeted disruption of the N-myc gene in the mouse. Development 117:1445-1455.

Sharpe J, Ahlgren U, Perry P, Hill B, Ross A, Hecksher-Sørensen J, Baldock R, Davidson D (2002) Optical projection tomography as a tool for 3D microscopy and gene expression studies. Science 296:541-545.

Shim K, Minowada G, Coling DE, Martin GR (2005) Sprouty2, a mouse deafness gene, regulates cell fate decisions in the auditory sensory epithelium by antagonizing FGF signaling. Dev Cell 8:553-564.

Soriano P (1999) Generalized lacZ expression with the ROSA26 Cre reporter strain. Nat Genet 21:70-71.

Trumpp A, Refaeli Y, Oskarsson T, Gasser S, Murphy M, Martin GR, Bishop JM (2001) c-Myc regulates mammalian body size by controlling cell number but not cell size. Nature 414:768-773.

van Bokhoven $\mathrm{H}$, Celli J, van Reeuwijk J, Rinne T, Glaudemans B, van Beusekom E, Rieu P, Newbury-Ecob RA, Chiang C, Brunner HG (2005) MYCN haploinsufficiency is associated with reduced brain size and intestinal atresias in Feingold syndrome. Nat Genet 37:465-467.

Vázquez-Echeverría C, Dominguez-Frutos E, Charnay P, Schimmang T, Pujades C (2008) Analysis of mouse kreisler mutants reveals new roles of hindbrain-derived signals in the establishment of the otic neurogenic domain. Dev Biol 322:167-178.

Woods C, Montcouquiol M, Kelley MW (2004) Math1 regulates development of the sensory epithelium in the mammalian cochlea. Nat Neurosci 7:1310-1318.

Yang W, Shen J, Wu M, Arsura M, FitzGerald M, Suldan Z, Kim DW, Hofmann CS, Pianetti S, Romieu-Mourez R, Freedman LP, Sonenshein GE (2001) Repression of transcription of the p27(Kip1) cyclin-dependent kinase inhibitor gene by c-Myc. Oncogene 20:1688-1702.

Zheng JL, Gao WQ (2000) Overexpression of Math1 induces robust production of extra hair cells in postnatal rat inner ears. Nat Neurosci 3:580 586. 